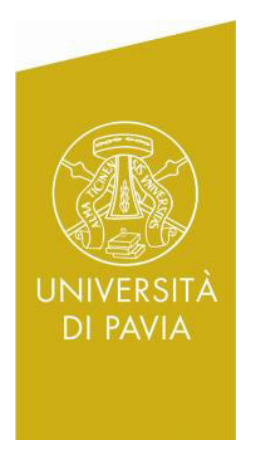

Department of Economics and Management DEM Working Paper Series

\title{
CoRisk: measuring systemic risk through default probability contagion
}

\author{
Paolo Giudici \\ (Università di Pavia) \\ Laura Parisi \\ (Università di Pavia) \\ \# 116 (02-16) \\ Via San Felice, 5 \\ I-27100 Pavia \\ http://epmq.unipv.eu/site/home.html
}

February 2016 


\title{
CoRisk: measuring systemic risk through default probability contagion*
}

\author{
Paolo Giudici and Laura Parisi \\ University of Pavia and NYU Stern School of Business \\ lparisi@stern.nyu.edu
}

\begin{abstract}
We propose a novel systemic risk measurement model, based on stochastic processes, correlation networks and conditional probabilities of default.

For each country we consider three different spread measures, one for each sector of the economy (sovereigns, corporates, banks), and we model each of them as a linear combination of two stochastic processes: a country-specific idiosyncratic component and a common systematic factor. We then build a partial correlation network model, and by combining it with the spread measures we derive the conditional default probabilities of each sector. Comparing them with the unconditional ones, we obtain the CoRisk, which measures the variation in the probability of default due to contagion effects.

Our measurement model is applied to understand the time evolution of systemic risk in the economies of the European monetary union, in the recent period. The results show that, overall, the sovereign crisis has increased systemic risks more than the financial crisis. In addition, peripheral countries turn out to be exporters, rather than importers of systemic risk, and, conversely, core countries.
\end{abstract}

Keywords: correlation networks, default probabilities, systemic risk, stochastic processes.

\section{Introduction}

\section{$1.1 \quad$ Background}

The last few years have witnessed an increasing research literature on systemic risk (for a definition see, for example, Allen and Gale, 2000; Acharya, 2009), with the aim of identifying the most contagious institutions and their transmission channels, and of studying the impact of monetary policies on default probabilities, especially during crisis periods (see, for example, Chong et al., 2006; Longstaff, 2010; Shleifer and Vishny, 2010).

Specific measures of systemic risk have been proposed for the banking sector; in particular, by Acharya et al. (2010), Adrian and Brunnermeier (2011), Brownlees and Engle (2012), Acharya et al. (2012), Dumitrescu and Banulescu (2014) and Hautsch et al. (2015) who, on the basis of market share prices, calculate the quantiles of the estimated loss probability distribution of a bank, conditional on the occurrence of an extreme event in the financial market. A similar approach has been applied to sovereign systemic risk, using bond interest rates, by Popescu and Turcu (2014).

The above approach is useful to establish policy thresholds aimed, in particular, at identifying the most systemic institutions. However, it is a bivariate approach, which allows to calculate the risk of an institution conditional on another or on a reference market but, on the other hand, it does not address the issue of how risks are transmitted between different institutions in a multivariate framework.

Trying to address the multivariate nature of systemic risk, researchers have recently proposed correlation network models, that combine the rich structure of financial networks (see, e.g., Lorenz

\footnotetext{
${ }^{*}$ We thank the 2015 Credit Risk Conference (Venice, 2015), the International Dauphine-ESSEC-SMU Conference on Systemic Risk (Singapore, 2015) and the CFE conference (London, 2015).
} 
et al., 2009; Battiston et al., 2012) with a parsimonious approach based on the dependence structure among market prices. The first contributions in this framework are Billio et al. (2012) and Diebold and Yilmaz (2014), who propose measures of connectedness based on Granger-causality tests and variance decompositions. Barigozzi and Brownlees (2013) and Ahelegbey et al. (2015) extend the approach introducing stochastic graphical models, while Das (2015) introduces the decomposition of a systemic risk measure into individual and network contributions.

Correlation network models are very useful to identify the most important channels of contagion in a cross-sectional perspective. However, similarly to bivariate measures, they can not be used as predictive models in a time-varying context. This is the main focus of econometric causal methods, as the ones proposed by Duffie et al. (2000), Lando and Nielsen (2010), Koopman et al. (2012) and Betz et al. (2014).

Both correlation networks and econometric models explain whether the default probability of a bank, a country, or of a company, depends on that of the others, or on a set of exogenous systematic risk factors. A different stream of research developed, among others, by Bartram et al. (2007), Ang and Longstaff (2012), Battiston et al. (2012) and Brownlees et al. (2014), models systemic risk in terms of univariate stochastic processes, that may also depend on systematic factors which are, however, endogenously determined. A further advantage of stochastic processes is that they are non-linear and time-dependent, and, therefore, can produce powerful early warning indicators.

We propose multivariate stochastic processes, whose interrelationships can be investigated by means of correlation network models: doing so, we combine the advantages of econometric models (predictive capability) with those of correlation networks (identification of channels of contagion) and of stochastic process models (endogeneity and non-linearity). To achieve our aim, we significantly extend the approach of Ang and Longstaff (2012) and Brownlees et al. (2014) by employing a multiple set of linear combinations of two stochastic processes (a systematic and an idiosyncratic one), rather than a single process.

In more detail, we consider three spread measures based on publicly available data: (a) the spread between the cost of debt for countries (interest rates on 10-years maturity government bonds) and a benchmark rate, which gives a measure of sovereign risk; (b) the spread between the cost of debt for corporates (interest rates on bank lendings) and a benchmark rate, which gives a measure of corporate risk; (c) the spread between the funding cost of the banking system (interest rates on deposits of non-financial corporates and households) and a benchmark rate, which gives a measure of bank risk.

We define three stochastic processes on the three spread measures: a probability of default can then be deduced from the estimated spreads, unconditionally for each sector and country. We then estimate a correlation network model, based on partial correlations, within each economic sector and across different countries and time, as suggested, although in a different modelling framework, by Gray et al. (2013), Ramsay and Sarlin (2015) and Schwaab et al. (2015). A new set of default probabilities can thus be calculated, conditionally on the dependence structure between countries and sectors defined by the estimated correlation networks.

The difference between the unconditional and the conditional probability of default can be employed to assess the effect of systemic contagion, introducing an appropriate novel measure, that will be named CoRisk. The introduction of conditional probabilities of default will also enable the calculation of the aggregate default probability for an entire country, thereby disentangling different risk sources: institution-specific and systemic, for each of the sovereign, corporate and bank sector.

In more detail, we will propose two different kinds of CoRisk: CoRisk $k_{i n}$, which measures how a sector of a country is influenced by the default probability of its neighbours in the network, thus providing a measure of its vulnerability; CoRisk $k_{\text {out }}$, which measures to what extent each economic sector of a country influences its neighbours in the graph, thus providing a measure of its systemic importance.

We remark that our proposal emphasises the difference between systematic and systemic risks: CoRisk, in fact, incorporates both of them, with the former deriving from the benchmark rate in the spread measures and the latter deriving from contagion effects obtained through correlation networks.

We also remark that our methodology makes explicit, using a clear probability metric, what suggested in Das (2015): a measure of systemic risk that can be decomposed in an individual node plus a network component. We also remark that a similar approach has been recently proposed by Mezei and Sarlin (2015), who define an aggregation operator in order to jointly estimate the importance of each single node as well as contagion effects deriving from links with other nodes in the graph. We improve both approaches by calculating node default probabilities for three different economic sectors in each country and by deriving link measures of contagion through 
partial correlations between linear combinations of stochastic processes: in such a way we can (a) allow for non-linear effects through stochastic differential equations, (b) allow for contagion effects, not only between, but also within each country, (c) disentangle the idiosyncratic and the systematic, as well as the institution-specific and the systemic components for the three economic sectors in each country. In addition, our CoRisk measure is allowed to be both positive or negative, meaning that the individual default probability of each economic sector or country can be increased or decreased according to the sign of partial correlations: from an economic viewpoint, this means that, when a country is negatively related to troubled countries, its final default probability decreases because it is perceived as a flight-to-quality haven.

Our proposed model will be applied and compared to data that concern four time windows: the pre-crisis period (2003-2006), the financial-crisis period (2007-2009), the sovereign-crisis period (2010-2012) and the post-crisis period (2013-2015), for the countries belonging to the Euro area.

Our main economic findings can be summarized as follows. First, in the Euro area the sovereign crisis has had a larger impact on systemic risk with respect to the financial crisis. A possible explanation consists in different ways peripheral and core economies reacted to the financial crisis: peripheral countries, with high public debts, had little fiscal space and, therefore, the financial crisis triggered their imbalances to emerge in the subsequent sovereign crisis. Second, the contribution of the bank and the sovereign sectors to systemic risk increased, in all countries, respectively during the financial and the sovereign crisis, with core economies mainly affected by contagion effects and peripheral countries characterised by high idiosyncratic $P D s$, exacerbated by within peripheral cluster contagion effects. Third, peripheral (core) countries are more exporter (importer) rather than importer (exporter) of systemic risks.

The paper is structured as follows: Section 2 describes the proposed models, with Section 2.1 introducing multivariate linear combinations of interest rate spread models and partial correlation networks and Section 2.2 defining default probabilities and CoRisk. Section 3 describes the application of the proposed models, with Section 3.1 presenting data and descriptive statistics, Section 3.2 presenting the empirical evidence obtained from multivariate stochastic processes and partial correlation networks and Section 3.3 presenting the obtained default probabilities and CoRisk measures. Finally, Section 4 concludes with some final remarks.

\section{Proposal}

\subsection{Multivariate Stochastic Processes}

For each country we consider the aggregate financial liabilities of three economic sectors: sovereign, (non-financial) corporates and banks.

For each given sector, and independently from the others, we assume that the time dynamics of the liabilities of each country, expressed by the evolution of the associated interest rate, can be described by a linear combination of two stochastic processes: a common systematic process and an idiosyncratic process. More formally, for each country $i=1, \ldots, N$ :

$$
Z_{t}^{i}=\alpha^{i} y_{t}^{i}-\beta^{i} S_{t}
$$

where $S_{t}$ stands for the systematic process, while $y_{t}^{i}$ represents the idiosyncratic process referred to country $i$; the parameter $\beta^{i}$ measures the weight of the systematic process, while $\alpha^{i}$ measures the weight of the idiosyncratic process, both on the general, complete process $Z_{t}^{i}$, that describes the resulting time-evolution of the interest spread.

We remark that the previous equation assumes that the systematic process is the same for all countries, but it differently influences each country-specific process $Z_{t}^{i}$, through the weight $\beta^{i}$. From an economic viewpoint, the above formulation expresses $Z_{t}^{i}$ as the difference between the cost of a long term debt and the cost of liquidity.

Both the systematic and the idiosyncratic processes can be modelled as CIR processes (Cox, Ingersoll and Ross, 1985), as follows:

$$
\left\{\begin{array}{l}
\mathrm{d} S_{t}=\left(a-v S_{t-1}\right) \mathrm{d} t+b \sqrt{S_{t-1}} \mathrm{~d} B_{t}, \\
\mathrm{~d} y_{t}^{i}=\left(\theta_{1}^{i}-\theta_{2}^{i} y_{t-1}^{i}\right) \mathrm{d} t+\theta_{3}^{i} \sqrt{y_{t-1}^{i}} \mathrm{~d} W_{t},
\end{array}\right.
$$

where $\mathrm{d} B_{t}$ and $\mathrm{d} W_{t}$ are two independent Brownian motions.

We then assume the following correlation structure: 


$$
\left\{\begin{array}{l}
\operatorname{Corr}\left[y_{t}^{i}, y_{t}^{j}\right]=\rho^{i j} \\
\operatorname{Corr}\left[S_{t}, y_{t}^{j}\right]=\gamma^{j}
\end{array}\right.
$$

Note that the first equation is consistent with the assumptions used in the formulation of multidimensional CIR processes (see e.g. Kalogeropoulos et al., 2011); the second one introduces an innovation in the literature, assuming a correlation between each idiosyncratic process and the systematic process $S_{t}$.

In this way we obtain a more general process able: (a) to capture both the systematic and the idiosyncratic components that may affect interest rate spread dynamics, using linear combinations of stochastic processes; (b) to model the correlation structure of interest rate spreads across different countries and sectors, by means of graphical network models, as we shall see later.

We now show the resulting expression of the instantaneous covariance matrix, for our multivariate linear combination of CIR processes.

First define:

$$
P=\left[\begin{array}{cccc}
1 & \rho^{12} & \ldots & \rho^{1 N} \\
\rho^{21} & 1 & \ldots & \rho^{2 N} \\
\vdots & \vdots & \ddots & \vdots \\
\rho^{N 1} & \rho^{N 2} & \ldots & 1
\end{array}\right], \quad \Gamma=\left[\begin{array}{c}
\gamma^{1} \\
\vdots \\
\gamma^{i} \\
\vdots \\
\gamma^{N}
\end{array}\right]
$$

where each element in $P$ is the correlation coefficient between the idiosyncratic processes of any two countries, while each element of $\Gamma$ is the correlation coefficient between any idiosyncratic process and the systematic process, as defined in (2.3).

The instantaneous covariance matrix $A$ can then be shown to be:

$$
A=\Phi \cdot \Theta^{T},
$$

where

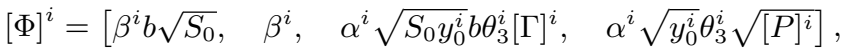

$$
\begin{aligned}
& {\left[\Theta^{T}\right]^{j}=\left[\begin{array}{c}
\beta^{j} b \sqrt{S_{0}} \\
\alpha^{j} \sqrt{S_{0} y_{0}^{j}} b \theta_{3}^{j}[\Gamma]^{j} \\
\beta^{j} \\
\alpha^{j} \sqrt{y_{0}^{j}} \theta_{3}^{j} \sqrt{[P]^{j}}
\end{array}\right] .}
\end{aligned}
$$

The parameters of the proposed process can be estimated extending results available for univariate stochastic processes (see e.g. Iacus, 2008), based on the maximization of the log-likelihood function.

To estimate the weights of the idiosyncratic $\left(\alpha^{i}\right)$ and the systematic $\left(\beta^{i}\right)$ processes, we consider a method of moments estimation procedure. Let $y^{i}$ and $s$ be the observed time vectors of (country specific) interest rates and of systematic rates. Let then $d^{i}=y^{i}-s$ be the observed vector of spreads. The weights can then be estimated as:

$$
\left\{\begin{array}{l}
\alpha^{i}=\operatorname{Corr}\left(d^{i}, y^{i}\right), \\
\beta^{i}=\operatorname{Corr}\left(d^{i}, s\right) .
\end{array}\right.
$$

From an economic viewpoint, it is important to understand the meaning of the weight coefficients $\alpha^{i}$ and $\beta^{i}$ : if they are both positive, it means that both the correlation between $d^{i}$ and $y^{i}$ and that between $d^{i}$ and $s$ are positive, which means that the idiosyncratic process component of $d^{i}$ increases faster than the systematic one: $\left|\frac{\partial y^{i}}{\partial t}\right|>\frac{\partial s}{\partial t}$. If the two coefficients are both negative, the systematic component, instead, changes faster than the idiosyncratic one: $\left|\frac{\partial s}{\partial t}\right|>\frac{\partial y^{i}}{\partial t}$.

The linear combination of stochastic processes proposed in (2.1) can be extended to allow for dependence between sovereign, corporate and bank spreads. More formally, suppose that all 
these measures, indicated respectively with the indexes $\{1,2,3\}$, are determined by the difference between an idiosyncratic and a common, systematic component, for each country $i=1, \ldots, N$ :

$$
\left\{\begin{array}{l}
Z_{t, 1}^{i}=\alpha_{1}^{i} y_{t, 1}^{i}-\beta_{1}^{i} S_{t} \\
Z_{t, 2}^{i}=\alpha_{2}^{i} y_{t, 2}^{j}-\beta_{2}^{i} S_{t} \\
Z_{t, 3}^{i}=\alpha_{3}^{i} y_{t, 3}^{k}-\beta_{3}^{i} S_{t}
\end{array}\right.
$$

In (2.7) the systematic component follows a univariate CIR process, while all idiosyncratic processes are modeled as a multivariate CIR:

$$
\left\{\begin{array}{l}
\mathrm{d} S_{t}=\left(a-v S_{t-1}\right) \mathrm{d} t+b \sqrt{S_{t-1}} \mathrm{~d} B_{t}, \\
\mathrm{~d} y_{t,\{1,2,3\}}^{i}=\left[\left(\theta_{1}\right)_{\{1,2,3\}}^{i}-\left(\theta_{2}\right)_{\{1,2,3\}}^{i} y_{t-1,\{1,2,3\}}^{i}\right] \mathrm{d} t+\left(\theta_{3}\right)_{\{1,2,3\}}^{i} \sqrt{y_{t-1,\{1,2,3\}}^{i}} \mathrm{~d} W_{t} .
\end{array}\right.
$$

We then assume the following correlation structure:

$$
\left\{\begin{array}{l}
\operatorname{Corr}\left[y_{t}^{m} ; y_{t}^{n}\right]=\rho^{m n} \\
\operatorname{Corr}\left[y_{t}^{m} ; S_{t}\right]=\gamma^{m}
\end{array}\right.
$$

where $\{m, n\} \in(V \times W)$, with $V=\{1, \ldots, N\}$ for the countries, and $W=\{1,2,3\}$ for the sectors of the economy.

From the above assumptions, the instantaneous covariance matrix of the new process turns out to be the same as that in (2.5), albeit with a different dimensionality, being a $3 N \times 3 N$ rather than a $N \times N$ matrix.

The estimated covariance matrix $\hat{A}$ can be employed to build a correlation network model between countries and economic sectors. However, such covariances can be misleading because they take into account only bivariate (marginal) relationships between interest spreads. We can obtain conditional covariances, that can adjust bivariate relationships by the presence of other variables. Conditional covariances can then be normalized to obtain conditional (partial) correlations.

Formally, let

$$
\hat{A}^{-1}
$$

be the inverse of the covariance matrix, with elements $a^{m n}$.The partial correlation between variables $Z^{m}$ and $Z^{n}$, conditional on the remaining variables in $V \times W, \rho_{m n V W}$ can be obtained as:

$$
\rho_{m n V W}=\frac{-a^{m n}}{\sqrt{a^{m m} a^{n n}}} .
$$

The estimated partial correlations can be employed to build a correlation network model, as shown in Giudici and Spelta (2015). Before doing so we add a further explanation of the partial correlation coefficient, and of its difference with respect to the (ordinary) marginal coefficient.

For $\{m, n\} \in(V \times W)$, let $S=(V \times W) \backslash\{m, n\}$. Suppose to express the dependence between spread measures through multiple linear equations in the following way:

$$
\left\{\begin{array}{l}
Z^{m}=a_{m}+\sum_{n \neq m} a_{m n \mid S} Z^{n} \\
Z^{n}=a_{n}+\sum_{m \neq n} a_{n m \mid S} Z^{m}
\end{array}\right.
$$

It can be shown that the partial correlation coefficient between $Z^{m}$ and $Z^{n}$, given all the other $3 N-2$ spread measures, can be interpreted as the (signed) geometric average between the multiple linear coefficients introduced in (2.10):

$$
\left|\rho_{m n \mid S}\right|=\left|\rho_{n m \mid S}\right|=\sqrt{a_{m n \mid S} \cdot a_{n m \mid S}} .
$$

Note that if we had only two components $(S=\varnothing)$, equation $(2.10)$ becomes:

$$
\left\{\begin{array}{l}
z^{m}=a+a_{m n} Z^{n} \\
z^{n}=a+a_{n m} Z^{m}
\end{array}\right.
$$

from which the (ordinary) marginal correlation $\rho_{m n}$ can be derived as the geometric average between the coefficients of the univariate linear models of equation (2.12): $\left|\rho_{m n}\right|=\left|\rho_{n m}\right|=$ $\sqrt{a_{m n} \cdot a_{n m}}$.

We can thus build a correlation network based on partial correlations, rather than on marginal correlations. To achieve this aim we proceed as follows. 
Let $G=(P, E)$ be an undirected graph, with vertex set $P=V \times W=\{1, \ldots, 3 N\}$, edge set $E=P \times P$, and a binary matrix, with elements $e_{m n}$, that describes whether pairs of vertices are (symmetrically) linked between each other $\left(e_{m n}=1\right)$ or not $\left(e_{m n}=0\right)$. An edge between two nodes $m$ and $n$ will then be present in the network if and only if the corresponding partial correlation $\rho_{m n \mid S}$ is significantly different from zero.

A simple way to detect partial correlations significance consists in using ordinary pairwise statistical t-tests, as partial correlations can also be interpreted as correlations between regression residuals. Alternatively, a more complex search over possible graphical models could be run, as described in Giudici and Spelta (2015).

\subsection{Default probabilities and CoRisk}

For each country and economic sector $m \in V \times W$, the probability of default, $P D_{t}^{m}$, can be obtained considering the expected dynamic of debt:

$$
D_{t+1}^{m}=\left(1-P D_{t}^{m}\right) e^{\alpha^{m} y_{t}^{m}} D_{t}^{m},
$$

where $D_{t+1}^{m}\left(D_{t}^{m}\right)$ is the total debt at time $t+1(t)$.

Note that the analogous dynamic of risk-free debt is the following:

$$
D_{t+1}^{m}=e^{\beta^{m} S_{t}} D_{t}^{m} .
$$

Assuming to be in an arbitrage-free context, we can equate (2.13) with (2.14) and obtain $P D_{t}^{m}:$

$$
P D_{t}^{m}=1-e^{-Z_{t}^{m}} .
$$

From the above equation, it is clear that if $Z_{t}^{m}$ decreases, the probability of default decreases, consistently with the definition of the process $Z_{t}^{m}$ as the spread between country specific interest rates and benchmark risk free rates.

We now aim at extending this definition of probability of default, which will be named institution-specific $P D$, to a notion that takes contagion into account. To this aim, we introduce $T P D^{m}$, the Total Probability of Default of an economic agent $m$, built as a function of both an idiosyncratic $\left(P D^{m}\right)$ and a systemic (CoRisk) component.

In order to derive TPD and, consequently, CoRisk, we combine the interpretation of partial correlation coefficients in (2.10) with the default probabilities derived in (2.15). Formally, let $m$ be the economic entity for which we want to measure the contagion effect, and $n$ be any other economic entity which may have an effect on $m$. By substituting $Z^{m}$ with $\ln \left(\frac{1}{1-T P D^{m}}\right)$ and $Z^{n}$ with $\ln \left(\frac{1}{1-P D^{n}}\right)$ in the first equation of $(2.10)$, it can be shown that:

$$
T P D^{m}=1-\left(1-P D^{m}\right) \cdot \prod_{n \in n e(m)}\left(1-P D^{n}\right)^{\rho_{m n \mid S}},
$$

where $n e(m)$ indicates all the first-order neighbours of $m$.

Let us define CoRisk $k_{i n}$ as a function of the survival probability of the neighbours $n$ connected to $m$, as follows:

$$
\text { CoRisk }_{i n}^{m}=1-\prod_{n \in n e(m)}\left(1-P D^{n}\right)^{\rho_{m n \mid S}} .
$$

It can be shown that, if we assume that $T P D>0$ (a rather obvious request), CoRisk $k_{i n}$ can be interpreted as the percentage variation of the complement of the default probability (the survival probability) due to contagion effects:

$$
\text { CoRisk }_{i n}^{m}=\frac{\left(1-P D^{m}\right)-\left(1-T P D^{m}\right)}{1-P D^{m}} .
$$

Economically, CoRisk ${ }_{i n}$ measures the change in the survival probability of an agent $m$ when contagion deriving from its neighbours $n \in n e(m)$ is included.

Similarly, we can measure the outgoing contagion effects, more precisely we can calculate to what extent institution $m$ affects its set of neighbours ne $(m)$. Formally, we can define CoRisk out $_{\text {t }}$ as follows:

$$
\operatorname{CoRisk}_{\text {out }}^{m}=1-\prod_{n \in n e(m)}\left(1-P D^{m}\right)^{\rho_{n m \mid S}}=1-\left(1-P D^{m}\right)^{\sum_{n \in n e(m)} \rho_{n m \mid S}}
$$


Note that the two definitions (2.17) and (2.19) introduce asymmetric effects: even if the graph is not oriented and, thus, it is symmetric, the incoming and outgoing contagion effects are different, since each node is associated to a different default probability and, consequently, its contagion effect towards its neighbours is different from the effect it receives from them. More precisely, if the two measures coincide, than the default probability of node $m$ is equal to the geometric average of the default probabilities of its neighbours: on the contrary, if CoRisk out $^{m}>$ CoRisk $_{i n}^{m}$ $(<)$, than the default probability of node $m$ is bigger (lower) than the geometric average of the default probabilities of its neighbours.

As an example, consider the graphs in Figure 1, where each node is associated to its institutionspecific $P D$ and each pair of nodes is associated to the corresponding partial correlation coefficient $\rho_{m n \mid S}$.
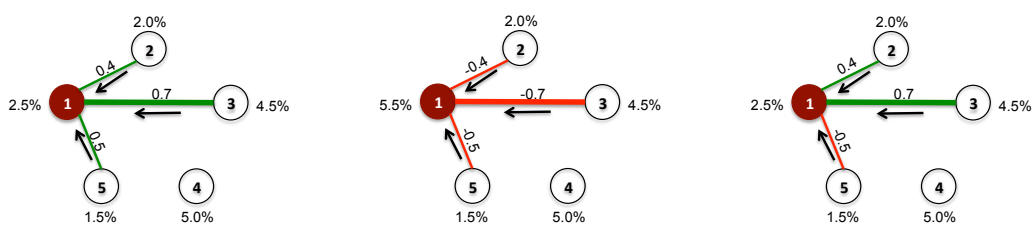

Figure 1: CoRisk $k_{i n}$, an illustrative example

In the first case, with all positive correlations, the final CoRisk $k_{i n}$ value is 0.047 , meaning that contagion has decreased the survival probability of node 1 by $4.7 \%$, bringing its default probability from $P D^{1}=2.9 \%$ to $T P D^{1}=7.2 \%$. In the second example, instead, all the correlation coefficients are negative, and the calculated CoRisk $k_{i n}$ becomes -0.049 , meaning that contagion has increased the survival probability of node 1 by $4.9 \%$. According to equation (2.16), the total $T P D^{1}$ has decreased, being equal to $0.87 \%$. Note that the CoRisk measure in this second case is not equal, in absolute value, to the one obtained in the previous example: this because the exponent $\rho$ introduces non-linear effects in the relationship in (2.17). In the last example, where both positive and negative correlations appear, the calculated CoRisk $k_{i n}$ measure is equal to 0.032 , meaning that contagion has decreased the survival probability of node 1 by $3.2 \%$, reaching a total default probability $T P D^{1}=5.6 \%$.
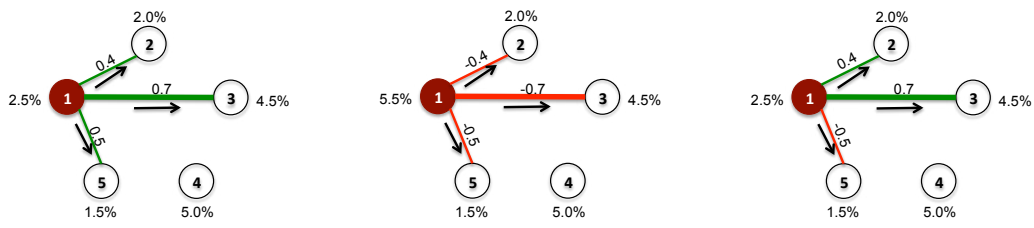

Figure 2: CoRisk $k_{\text {out }}$, an illustrative example

Figure 2 reports the same graphs as in Figure 1, but we now concentrate on the outgoing effects in order to understand how node 1 affects its neighbours. In the first example, the overall CoRisk $_{\text {out }}$ is equal to 0.040: this result is lower with respect to the CoRisk in $_{\text {value because }}$ the incoming contagion is highly affected by the large default probability of node 3. Similarly, in the second situation the final CoRisk $k_{\text {out }}$ is -0.095 . This result is lower than the corresponding CoRisk in $_{\text {n }}$ because, now, the default probability of node 1 is much bigger than the default probabilities of its neighbours: consequently, the contagion effect due to negative correlations is amplified, meaning that a negative relation with node 1 strongly decreases the default probability of the set ne(1). In the last example the calculated CoRisk $k_{\text {out }}$ measure is equal to 0.015 , lower than CoRisk in as in the first example.

From a mathematical viewpoint, CoRisk (both in and out) is expressed as a function of partial correlations and default probabilities. By remembering that $\rho_{m n \mid S} \in[-1,1]$ and $P D \in[0,1]$, CoRisk is thus a function $f: \Re^{2} \rightarrow \Re$, in particular $f(x, y):[-1,1] \times[0,1] \rightarrow(-\infty, 1]$.

In order to better interpret this measure, it is important to study its limit conditions. More precisely, CoRisk is equal to zero when, for all the first-order neighbours, one of the two following conditions holds:

$$
\left\{\begin{array}{l}
P D^{n}=0, \quad \forall n \in n e(m) ; \\
\rho_{m n \mid S}=0, \quad \forall n \in n e(m) .
\end{array}\right.
$$


This is consistent with the definition of CoRisk, meaning that the contribution to the default probability of a country $m$ that derives from contagion effects is null (a) if all its neighbours have zero default probability, or (b) if country $m$ is not partially related to any other country.

Secondly, CoRisk reaches its highest value 1 if $\exists n \in n e(m)$ s.t. $P D^{n}=1$, meaning that the highest contribution to systemic risk of country $m$ occurs when at least one of its neighbours $n$ is in default.

Finally, it is interesting to observe that contagion risk is negative when partial correlations prevail: in particular, CoRisk $\rightarrow-\infty$ if $\exists n \in n e(m)$ s.t. the two following conditions simultaneously hold:

$$
\left\{\begin{array}{l}
P D^{n} \rightarrow 1, \\
\rho_{m n \mid S} \rightarrow-1 .
\end{array}\right.
$$

The total default probabilities introduced in (2.16) are referred to index $m$, and are thus defined for each economic sector within each country. However, it is interesting to calculate the total default probability of different countries, obtained by aggregating the default probabilities of their economic sectors: it is reasonable to assume that a country will default if at least one of its economic sector defaults. In order to achieve this objective, each $T P D^{m}$ can be considered as a conditional probability with respect to all the other neighbours $n e(m)$. In particular, denoting with $A_{1}^{i}, A_{2}^{i}$ and $A_{3}^{i}$ the sets of defaults for, respectively, the sovereign, corporate and bank sectors of country $i$, we are interested in deriving $P\left(\bigcup_{j \in W} A_{j}^{i} \mid S^{i}\right)$, where $S^{i}=\left\{A^{m} ; \forall m \in V \times W, m \in\right.$ $n e(i, j), m \neq(i, j)\}$.

It can be shown that the aggregate total default probability of country $i$ is the following:

$$
T P D_{\text {country }}^{i}=1-\left[1-\operatorname{Pr}\left(A_{2}^{i} \mid A_{1}^{i}, A_{3}^{i}, S^{i}\right)\right] \cdot\left[1-\operatorname{Pr}\left(A_{3}^{i} \mid A_{1}^{i}, S^{i}\right)\right] \cdot\left[1-\operatorname{Pr}\left(A_{1}^{i} \mid S^{i}\right)\right],
$$

where the three probabilities in (2.22) are the TPD derived through (2.16) by considering, respectively, all neighbours, all neighbours but the corporate sector of country $i$, all neighbours but the corporate and bank sectors of country $i$.

\section{Application}

We focus on eleven european countries: Austria, Belgium, Finland, France, Germany and the Netherlands (core countries); Greece, Ireland, Italy, Portugal and Spain (peripheral countries).

For each country we consider three idiosyncratic components, for sovereign, corporate and bank risk: (a) interest rates on government bonds, (b) aggregate interest rates on bank loans to nonfinancial corporates, (c) aggregate interest rates on bank deposits from non-financial corporates and households. Concerning the common systematic component, there are many choices for a benchmark rate: we suggest a rate that reflects the impact of the European Central Bank monetary policy, such as the 3-months Euribor.

In order to evaluate the evolution of the resulting $N=11 \times 3$-dimensional system of interest rate spreads, we have considered four different time windows: (a) the pre-crisis period (20032006), (b) the financial crisis period (2007-2009), (c) the sovereign crisis period (2010-2012) and (d) the post-crisis period (2013-2015).

All data are publicly available and have been selected with a monthly frequency.

\subsection{Descriptive statistics}

A summary statistics of the data is shown in Table 1: for each of the three economic sectors, data have been grouped in four time windows, and means, standard deviations as well as correlations with the Euribor interest rate are reported.

From Table 1 note that interest rates on loans have the highest correlation coefficients with Euribor interest rates, during all time-windows and in almost all countries. The same correlations vary for interest rates on government bonds: low during the pre-crisis period and higher afterwards (with the exception of Greece). The correlations of bank interest rates with the Euribor follow a similar pattern, being very low until 2012 in almost all countries, and strongly positive afterwards.

The time evolution of the interest rate processes for the sovereign sector can be observed in Figure 3.

Figure 3 shows that interest rates on government bonds were initially very similar, while in 2010 they started diverging: decreasing in core countries and increasing in peripheral countries. 


\begin{tabular}{llll|lll|lll}
\multicolumn{10}{c}{ Pre-crisis Period } \\
\hline Country & Mean & $y_{t, 1}($ Sov, $\%)$ & \multicolumn{3}{c|}{$y_{t, 2}$ (Corp, \%) } & \multicolumn{3}{c}{$y_{t, 3}$ (Bank, \%) } \\
\hline Aus & 3.866 & 0.368 & -0.033 & 4.096 & 0.289 & 0.371 & 3.248 & 0.189 & -0.463 \\
Bel & 3.894 & 0.366 & -0.041 & 4.525 & 0.225 & 0.171 & 4.117 & 0.251 & -0.415 \\
Fin & 3.845 & 0.381 & 0.009 & 3.640 & 0.312 & 0.791 & 2.664 & 0.225 & 0.202 \\
Fra & 3.859 & 0.352 & -0.020 & 4.351 & 0.159 & 0.399 & 3.669 & 0.102 & -0.389 \\
Ger & 3.806 & 0.352 & 0.008 & 4.982 & 0.189 & -0.065 & 3.142 & 0.274 & -0.540 \\
Gre & 4.045 & 0.343 & 0.109 & 5.659 & 0.264 & 0.880 & 0.402 & 0.117 & 0.606 \\
Ire & 3.826 & 0.378 & -0.002 & 4.675 & 0.372 & 0.634 & 2.564 & 0.202 & 0.806 \\
Ita & 4.027 & 0.349 & 0.096 & 4.538 & 0.307 & 0.654 & 3.131 & 0.258 & 0.140 \\
Net & 3.843 & 0.362 & -0.015 & 4.693 & 0.207 & 0.272 & 3.971 & 0.269 & -0.074 \\
Por & 3.919 & 0.358 & 0.071 & 4.548 & 0.321 & 0.929 & 3.033 & 0.252 & 0.301 \\
Spa & 3.850 & 0.362 & -0.019 & 3.619 & 0.324 & 0.780 & 2.487 & 0.174 & 0.144 \\
\hline
\end{tabular}

\begin{tabular}{|c|c|c|c|c|c|c|c|c|c|}
\hline \multicolumn{10}{|c|}{ Financial-crisis Period } \\
\hline & \multicolumn{3}{|c|}{$y_{t, 1}($ Sov, \%) } & \multicolumn{3}{|c|}{$y_{t, 2}($ Corp, \%) } & \multicolumn{3}{|c|}{$y_{t, 3}($ Bank, \%) } \\
\hline Country & Mean & SD & Cor-Eur & Mean & SD & Cor-Eur & Mean & SD & Cor-Eur \\
\hline Aus & 4.198 & 0.298 & 0.752 & 4.531 & 0.943 & 0.967 & 3.352 & 0.179 & 0.383 \\
\hline Bel & 4.216 & 0.322 & 0.834 & 4.754 & 0.671 & 0.986 & 4.009 & 0.156 & 0.427 \\
\hline Fin & 4.107 & 0.350 & 0.847 & 4.378 & 1.103 & 0.980 & 2.968 & 0.355 & 0.838 \\
\hline Fra & 4.063 & 0.370 & 0.852 & 4.710 & 0.587 & 0.956 & 3.565 & 0.059 & 0.353 \\
\hline Ger & 3.808 & 0.502 & 0.840 & 4.961 & 0.579 & 0.986 & 2.688 & 0.047 & 0.726 \\
\hline Gre & 4.826 & 0.437 & -0.417 & 6.326 & 0.777 & 0.972 & 1.386 & 0.523 & -0.175 \\
\hline Ire & 4.686 & 0.481 & -0.668 & 5.321 & 1.274 & 0.990 & 2.427 & 0.457 & 0.748 \\
\hline Ita & 4.494 & 0.268 & 0.644 & 5.208 & 1.062 & 0.968 & 3.182 & 0.533 & 0.972 \\
\hline Net & 4.067 & 0.352 & 0.846 & 4.751 & 0.797 & 0.994 & 3.758 & 0.053 & 0.153 \\
\hline Por & 4.385 & 0.292 & 0.605 & 5.416 & 1.031 & 0.949 & 3.058 & 0.407 & 0.930 \\
\hline Spa & 4.218 & 0.278 & 0.756 & 4.873 & 0.789 & 0.904 & 2.717 & 0.234 & 0.528 \\
\hline
\end{tabular}

\begin{tabular}{llll|lll|lll}
\multicolumn{10}{c}{ Sovereign-crisis Period } \\
\hline & \multicolumn{3}{c}{$y_{t, 1}($ Sov, $\%)$} & \multicolumn{3}{c}{$y_{t, 2}$ (Corp, \%) } & \multicolumn{3}{c}{$y_{t, 3}($ Bank, \%) } \\
\hline Country & Mean & SD & Cor-Eur & Mean & SD & Cor-Eur & Mean & SD & Cor-Eur \\
\hline Aus & 2.972 & 0.587 & 0.586 & 2.845 & 0.232 & 0.934 & 2.297 & 0.104 & 0.256 \\
Bel & 3.565 & 0.660 & 0.877 & 3.460 & 0.169 & 0.920 & 3.182 & 0.177 & -0.136 \\
Fin & 2.634 & 0.642 & 0.499 & 2.450 & 0.269 & 0.971 & 2.138 & 0.129 & -0.232 \\
Fra & 2.992 & 0.482 & 0.618 & 3.318 & 0.144 & 0.823 & 3.150 & 0.080 & 0.023 \\
Ger & 2.282 & 0.697 & 0.383 & 3.837 & 0.191 & 0.933 & 2.564 & 0.095 & 0.500 \\
Gre & 15.780 & 6.526 & 0.011 & 5.649 & 0.553 & 0.313 & 2.491 & 0.312 & -0.265 \\
Ire & 7.171 & 2.136 & 0.832 & 3.323 & 0.281 & 0.869 & 1.939 & 0.399 & -0.182 \\
Ita & 4.984 & 0.891 & 0.305 & 3.505 & 0.332 & 0.221 & 2.784 & 0.441 & -0.470 \\
Net & 2.638 & 0.622 & 0.469 & 3.436 & 0.192 & 0.991 & 3.801 & 0.139 & 0.026 \\
Por & 8.728 & 2.953 & 0.426 & 4.264 & 0.676 & 0.203 & 2.511 & 0.456 & -0.172 \\
Spa & 5.179 & 0.815 & -0.008 & 3.532 & 0.260 & 0.404 & 2.486 & 0.282 & 0.051 \\
\hline
\end{tabular}

\begin{tabular}{llll|lll|lll}
\hline \multicolumn{1}{c}{ Post-crisis Period } \\
\hline & \multicolumn{1}{c}{$y_{t, 1}($ Sov, \%) } & \multicolumn{3}{c}{$y_{t, 2}$ (Corp, \%) } & \multicolumn{3}{c}{$y_{t, 3}$ (Bank, \%) } \\
\hline Country & Mean & SD & Cor-Eur & Mean & SD & Cor-Eur & Mean & SD & Cor-Eur \\
\hline Aus & 1.430 & 0.608 & 0.829 & 2.323 & 0.097 & 0.969 & 1.681 & 0.206 & 0.837 \\
Bel & 1.676 & 0.740 & 0.854 & 2.851 & 0.190 & 0.950 & 2.697 & 0.222 & 0.847 \\
Fin & 1.357 & 0.564 & 0.864 & 1.870 & 0.110 & 0.964 & 1.587 & 0.330 & 0.786 \\
Fra & 1.589 & 0.650 & 0.856 & 2.725 & 0.194 & 0.856 & 2.864 & 0.124 & 0.835 \\
Ger & 1.091 & 0.521 & 0.857 & 3.085 & 0.204 & 0.911 & 2.015 & 0.192 & 0.833 \\
Gre & 8.943 & 1.881 & -0.293 & 5.442 & 0.366 & 0.921 & 2.161 & 0.971 & 0.891 \\
Ire & 2.485 & 1.158 & 0.816 & 3.095 & 0.071 & -0.496 & 1.892 & 0.280 & 0.630 \\
Ita & 3.014 & 1.133 & 0.801 & 3.511 & 0.237 & 0.947 & 2.896 & 0.368 & 0.578 \\
Net & 1.387 & 0.612 & 0.850 & 2.908 & 0.174 & 0.953 & 3.560 & 0.170 & 0.820 \\
Por & 4.205 & 1.708 & 0.718 & 4.108 & 0.338 & 0.919 & 2.730 & 0.434 & 0.952 \\
Spa & 3.045 & 1.266 & 0.728 & 3.129 & 0.360 & 0.935 & 2.258 & 0.348 & 0.800 \\
\hline \hline
\end{tabular}

Table 1: Summary statistics for interest rates on government bonds $\left(y_{t, 1}^{i}\right)$, interest rates on loans to non-financial corporates $\left(y_{t, 2}^{i}\right)$ and interest rates on deposits to families and non-financial corporates $\left(y_{t, 3}^{i}\right)$, for the four time-windows

Greece, Ireland and Portugal present the highest volatility, corresponding to their sovereign crisis in 2010-2011, followed by Italy and Spain and, to a lesser extent, Belgium.

The time evolution of the interest rate processes for the corporate sector can be observed in Figure 4 .

From Figure 4 one can notice that interest rates on loans to non-financial corporates differ across the main european countries in a manner that is consistent across time. In particular, Greece and Portugal have the highest values while Finland and Austria present the lowest ones. The interest curves of corporates do not show substantial overlaps: they all increase during the financial crisis of 2008 and, to a lesser extent, during the sovereign crisis of 2011. All rates show positive correlations with the Euribor dynamics. Overall, the scale of variation of corporate rates is much smaller than that of sovereign rates, especially in peripheral countries. 


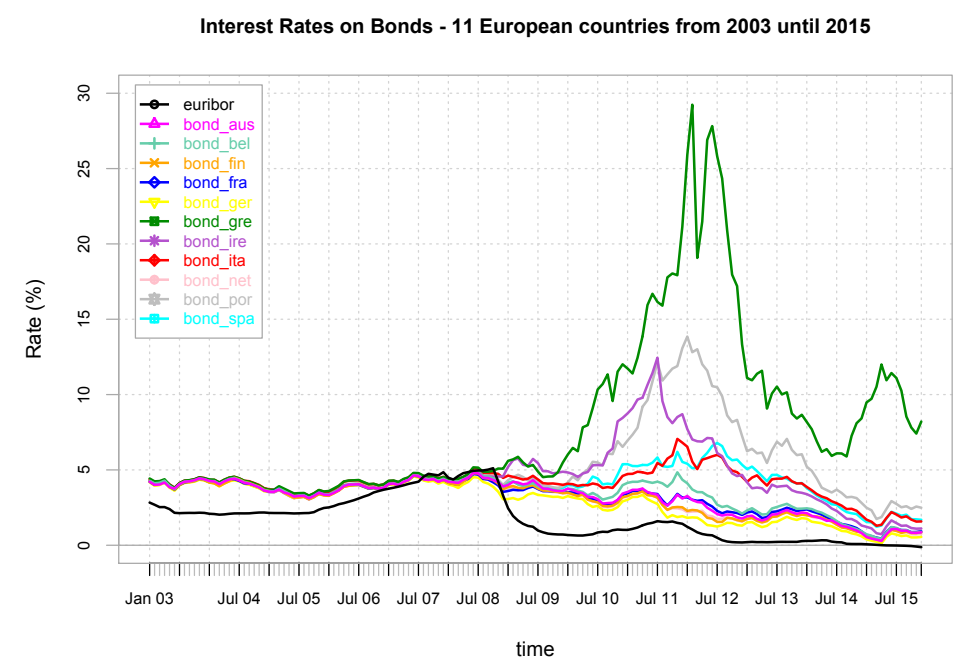

Figure 3: Monthly time evolution of 10-years maturity bond interest rates and of the 3-months Euribor, from January 2003 until December 2015

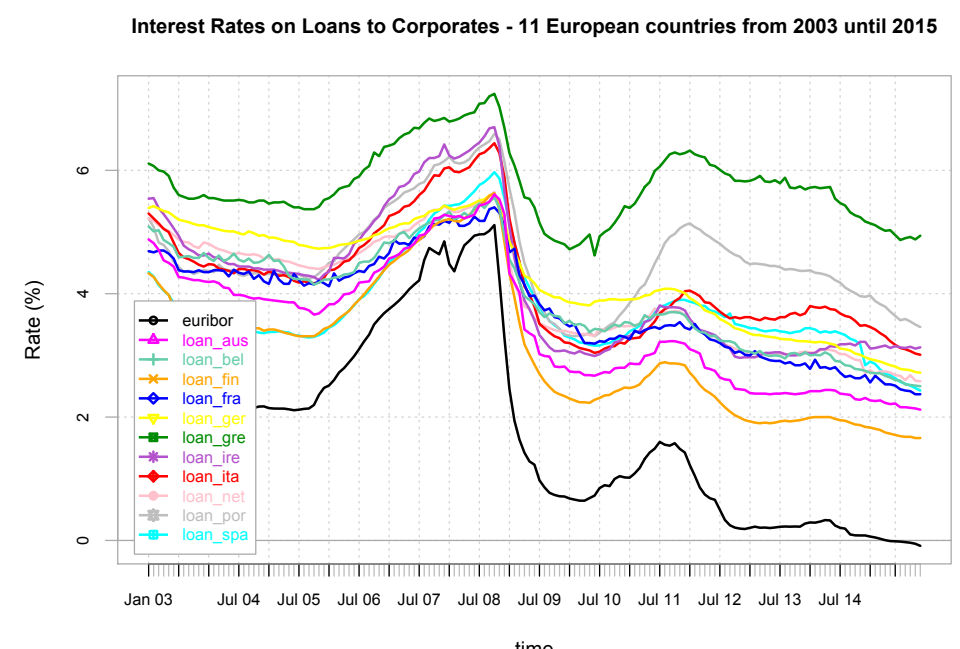

Figure 4: Monthly time evolution of interest rates on loans to non-financial corporates and of the 3-months Euribor, from January 2003 until December 2015 5.

The time evolution of the interest rate processes for the bank sector can be observed in Figure

Figure 5 shows an interest rate pattern substantially different with respect to sovereigns and non-financial corporates. The highest rates can be detected in France, Belgium and the Netherlands consistently through time, while the curves of the other countries do overlap: this is especially true for peripheral countries, affected not only by the financial crisis but also by the sovereign crisis. In addition, while France, Belgium, the Netherlands and Germany show low correlations with the Euribor rate across time, the other countries increase their correlations, especially after 2012. Overall, the scale of variation of bank rates is slightly lower than that of corporate ones.

\subsection{Multivariate stochastic processes}

The first step in model estimation consists in deriving the coefficients in (2.2), for the three sectors of each country (and for the common systematic process). The Appendix contains such estimated coefficients, along with the estimates of the relative weights of the idiosyncratic and systematic 


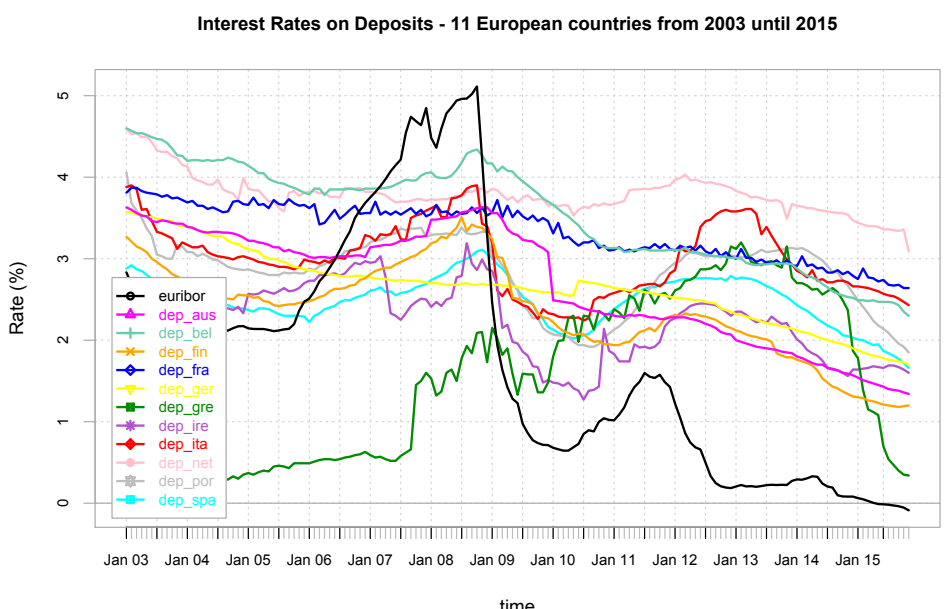

Figure 5: Monthly time evolution of interest rates on deposits and of the 3-months Euribor, from January 2003 until December 2015

processes.

From Table 6 note that, during the two crisis periods, all the parameters (drift and volatility terms) of the three processes are sensibly higher in peripheral countries. In the post-crisis period, the drift returns to the initial values (with the exception of Greece), but the volatility remains quite high.

From Table 7 note that, during the pre-crisis period, both weights $\alpha_{1}$ and $\beta_{1}$ are negative for the sovereign and bank sectors in all countries: the systematic component, therefore, changes faster than the idiosyncratic one. On the contrary, during the post-crisis years, almost all weights are positive, meaning that the idiosyncratic component changes faster than the systematic one, consistently with the current situation of almost zero monetary rates. Overall, the weights of the processes change over time, but such changes are homogeneous and similar across the eleven considered countries through time.

We now derive, according to (2.9), the network models obtained for the sovereign, corporate and bank spreads. To achieve this aim it is necessary to calculate, within each sector $j$, the inverse correlation matrix of the spreads $Z_{t, j}^{i}$ for the eleven countries $i$ and in each time period $t$, the resulting partial correlation coefficients, and the $p$-values associated to the significance t-test of each partial correlation. As a general rule, a connection between two countries will be removed when the $p$-value is greater than $\alpha=0.10$.

We can thus derive the partial correlation network for each sector and for the four different time windows. The results are shown in Figure 6, in which the green lines stand for positive significant partial correlations, while red lines indicate negative significant partial correlations; moreover, the ticker the line, the stronger the connection.

Comparing the sovereign partial correlation networks in Figure 6 note that their pattern has substantially changed over the years: in the pre-crisis period the overall number of significant correlations is quite high; during the financial crisis the number of significant correlations decreases; during the sovereign crisis correlations further decreases, and a "clustering effect" that separates core and peripheral economies in two quite distinct subgraphs emerges. Last, in the post-crisis period the partial correlation pattern returns to the pre-crisis situation, however with a persisting clustering effect, emphasized not only by positive within subgraph correlations, but also by negative ones between the two subgraphs.

Bank partial correlation networks, similarly to sovereign ones, are quite connected in the first two periods, and become sparser afterwards. In this case, the clustering effect becomes evident in the last, rather than in the third period. This time delay may also be due to the different kind of data used for banks with respect to sovereigns: the latter are market-based data, characterized by quick reactions to the economic perspectives of a country; the former, instead, depend upon banks' decisions and are characterized by a viscosity degree with respect to the external environment.

By analyzing the corporate partial correlation networks in Figure 6, note that also in this case the partial correlation pattern has substantially changed over the years. During the precrisis period the overall number of significant correlations is quite high, similarly to the sovereign 

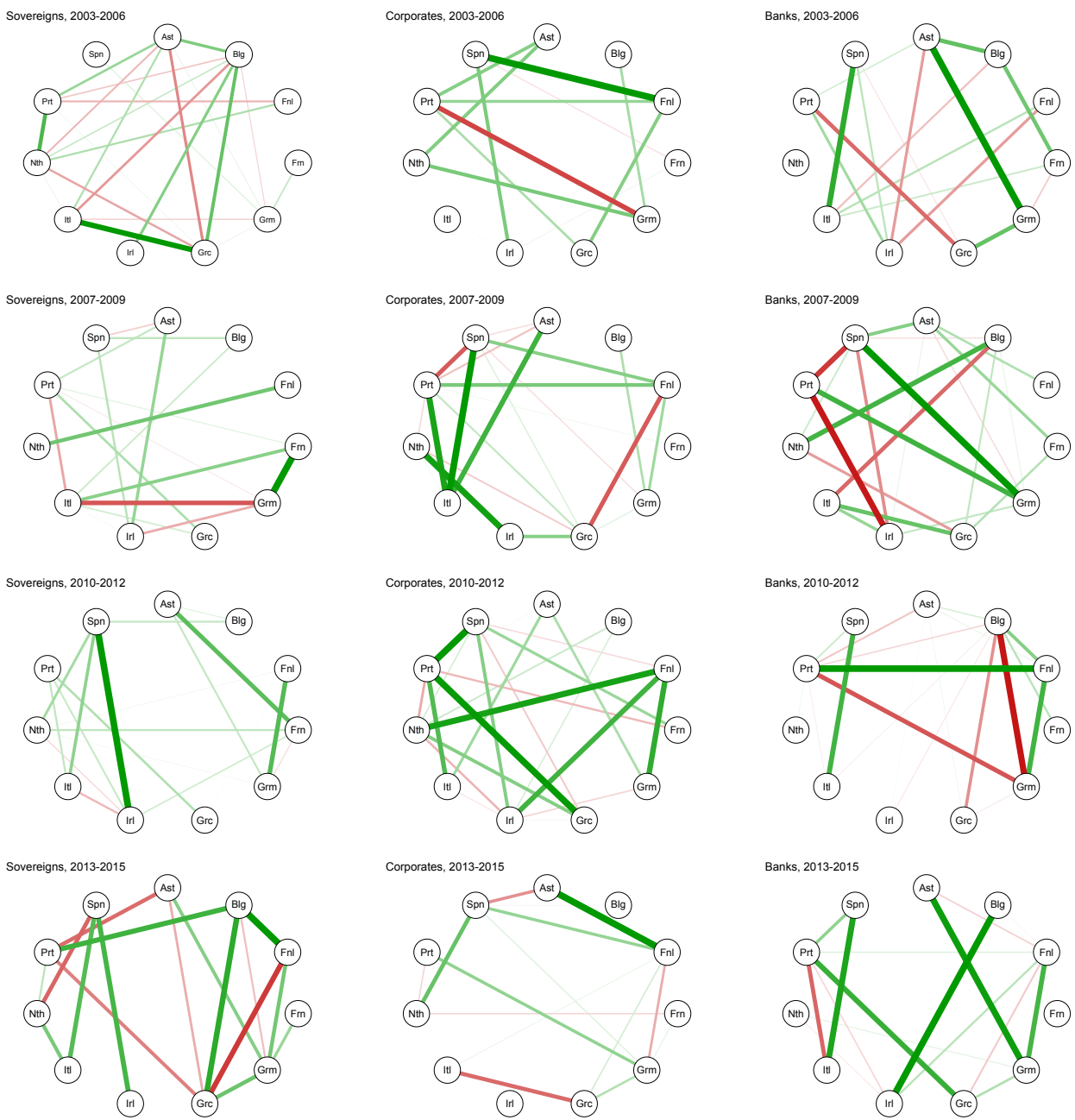

Figure 6: Network graphs for the eleven european countries considered in the sample, based on $Z_{t, 1}^{i}$ (left), $Z_{t, 2}^{i}$ (middle) and $Z_{t, 3}^{i}$ (right), for the pre-crisis (first row), financial-crisis (second row), sovereign-crisis (third row) and post-crisis (fourth row) periods

and bank ones. During the financial crisis the number of significant correlations substantially decreases; during the sovereign crisis significant correlations increase again in number, and they drop in the last period, characterized by low growth and close-to-zero Euribor interest rates. Differently from what observed in the other two economic sectors, a clustering effect between core and peripheral countries is not evident: a possible explanation is that corporate interest rates are highly and constantly correlated with Euribor rates across time and, thus, clustering effects become less significant.

\subsection{Default probabilities and CoRisk}

After having estimated all the process parameters and the partial correlation networks, we are now able to calculate the institution-specific probability of default of each sovereign $\left(P D_{t, 1}^{i}\right)$, corporate $\left(P D_{t, 2}^{i}\right)$ and bank $\left(P D_{t, 3}^{i}\right)$ sector in each country $i$, based respectively on the spread measures $Z_{t, 1}^{i}, Z_{t, 2}^{i}$ and $Z_{t, 3}^{i}$ according to equation (2.15). By using such $P D s$ and the correlation networks, we can calculate the CoRisk $k_{i n}$ measures and, through them, the total default probability of each economic sector in each country $T P D_{t,\{1,2,3\}}^{i}$ as in (2.16).

Summary statistics of CoRisk $k_{i n}$ for the different time windows are shown in Table 2. The corresponding time evolution is shown in Figure 7.

Let us firstly consider the sovereign graphs in Figure 7. By looking at the single institutionspecific $P D$ (top graphs), it is clear that Greece presents the most critical situation, with the highest $P D$ values. Portugal has similar, but lower results. Ireland presents an anticipated 


\begin{tabular}{|c|c|c|c|c|c|c|c|c|c|c|c|c|}
\hline \multicolumn{13}{|c|}{ Pre-crisis Period } \\
\hline & \multicolumn{4}{|c|}{ CoRisk $_{\text {sov }}(\%)$} & \multicolumn{4}{|c|}{$\operatorname{CoRisk}_{\text {corp }}(\%)$} & \multicolumn{4}{|c|}{ CoRisk $_{\text {bank }}(\%)$} \\
\hline Country & Mean & SD & Min & $\operatorname{Max}$ & Mean & SD & Min & Max & Mean & SD & Min & Max \\
\hline Aus & 1.36 & 0.30 & 1.09 & 2.23 & 1.91 & 0.09 & 1.78 & 2.11 & 1.90 & 0.18 & 1.68 & 2.31 \\
\hline Bel & 1.42 & 0.32 & 1.14 & 2.34 & 0.49 & 0.09 & 0.26 & 0.56 & 0.78 & 0.28 & 0.44 & 1.49 \\
\hline Fin & -0.01 & 0.01 & -0.03 & 0.01 & 4.28 & 0.32 & 3.97 & 5.16 & 0.52 & 0.13 & 0.39 & 0.84 \\
\hline Fra & 0.60 & 0.14 & 0.47 & 1.01 & 0.92 & 0.09 & 0.73 & 1.07 & 1.11 & 0.31 & 0.84 & 2.01 \\
\hline Ger & 0.44 & 0.13 & 0.32 & 0.79 & 2.01 & 0.23 & 1.56 & 2.33 & 2.20 & 0.55 & 1.75 & 3.87 \\
\hline Gre & 0.96 & 0.17 & 0.82 & 1.45 & 0.99 & 0.18 & 0.83 & 1.51 & -0.37 & 0.08 & -0.64 & -0.30 \\
\hline Ire & 0.89 & 0.20 & 0.71 & 1.46 & 1.21 & 0.13 & 1.08 & 1.54 & 2.09 & 0.25 & 1.65 & 2.56 \\
\hline Ita & 0.91 & 0.16 & 0.78 & 1.36 & 0.92 & 0.07 & 0.83 & 1.10 & 1.90 & 0.15 & 1.78 & 2.30 \\
\hline Net & 0.95 & 0.22 & 0.75 & 1.57 & 1.97 & 0.17 & 1.67 & 2.23 & 0.60 & 0.09 & 0.52 & 0.85 \\
\hline Por & 0.58 & 0.14 & 0.44 & 0.98 & 1.15 & 0.26 & 0.94 & 1.87 & -0.04 & 0.15 & -0.21 & 0.30 \\
\hline Spa & 0.51 & 0.12 & 0.40 & 0.86 & 1.25 & 0.12 & 1.10 & 1.54 & 1.52 & 0.30 & 1.25 & 2.34 \\
\hline \multicolumn{13}{|c|}{ Financial-crisis Period } \\
\hline & \multicolumn{4}{|c|}{ CoRisk $_{\text {sov }}(\%)$} & \multicolumn{4}{|c|}{ CoRisk $_{\text {corp }}(\%)$} & \multicolumn{4}{|c|}{ CoRisk $_{\text {bank }}(\%)$} \\
\hline Country & Mean & SD & Min & $\operatorname{Max}$ & Mean & SD & Min & Max & Mean & SD & Min & $\operatorname{Max}$ \\
\hline Aus & 1.86 & 0.78 & 0.97 & 3.52 & -0.04 & 0.16 & -0.54 & 0.13 & 6.86 & 1.56 & 4.08 & 8.98 \\
\hline Bel & 4.82 & 1.73 & 2.46 & 8.19 & -0.20 & 0.36 & -0.75 & 0.14 & 4.17 & 0.55 & 3.07 & 4.98 \\
\hline Fin & 3.98 & 1.40 & 2.02 & 6.62 & 2.05 & 1.61 & 0.11 & 5.35 & 3.60 & 0.91 & 1.98 & 4.83 \\
\hline Fra & 6.66 & 2.65 & 3.76 & 12.13 & 1.26 & 0.52 & 0.43 & 2.10 & 5.32 & 1.40 & 2.84 & 7.11 \\
\hline Ger & -2.18 & 0.97 & -4.11 & -1.00 & 5.94 & 2.49 & 2.02 & 9.40 & 7.79 & 1.76 & 4.32 & 10.06 \\
\hline Gre & 3.19 & 1.34 & 1.71 & 6.00 & 2.12 & 1.28 & 0.58 & 4.63 & 3.19 & 1.15 & 1.24 & 4.58 \\
\hline Ire & 1.28 & 0.69 & 0.34 & 2.29 & 5.44 & 2.34 & 2.56 & 10.83 & -1.78 & 0.63 & -2.52 & -0.62 \\
\hline Ita & -0.06 & 0.67 & -0.92 & 0.94 & 7.37 & 3.43 & 2.38 & 13.57 & 2.86 & 0.51 & 2.13 & 4.01 \\
\hline Net & 3.10 & 1.10 & 1.32 & 4.40 & 2.06 & 1.30 & -0.01 & 3.85 & 3.77 & 1.18 & 1.77 & 5.27 \\
\hline Por & 1.96 & 0.71 & 0.74 & 2.80 & 2.70 & 1.25 & 0.75 & 4.79 & -1.80 & 0.34 & -2.36 & -1.28 \\
\hline Spa & 1.79 & 0.71 & 0.94 & 3.25 & 2.14 & 1.14 & 0.35 & 3.65 & -1.07 & 1.05 & -2.19 & 0.59 \\
\hline \multicolumn{13}{|c|}{ Sovereign-crisis Period } \\
\hline & \multicolumn{4}{|c|}{ CoRisk $_{\text {sov }}(\%)$} & \multicolumn{4}{|c|}{ CoRisk corp $_{\text {co }}(\%)$} & \multicolumn{4}{|c|}{ CoRisk $_{\text {bank }}(\%)$} \\
\hline Country & Mean & SD & Min & $\operatorname{Max}$ & Mean & SD & Min & $\operatorname{Max}$ & Mean & SD & Min & $\operatorname{Max}$ \\
\hline Aus & 2.86 & 0.53 & 1.73 & 3.62 & 3.21 & 0.48 & 2.40 & 3.98 & 2.45 & 0.62 & 1.35 & 3.44 \\
\hline Bel & 2.59 & 0.28 & 2.17 & 3.15 & 0.44 & 0.30 & -0.16 & 0.87 & -1.63 & 0.34 & -2.19 & -1.11 \\
\hline Fin & 1.47 & 0.39 & 0.77 & 2.09 & 5.04 & 0.86 & 3.60 & 6.42 & 4.29 & 0.88 & 2.86 & 5.74 \\
\hline Fra & 4.02 & 0.89 & 2.65 & 6.08 & 0.66 & 0.21 & 0.23 & 0.95 & 1.95 & 0.30 & 1.43 & 2.45 \\
\hline Ger & 1.78 & 0.45 & 0.97 & 2.44 & -0.40 & 0.28 & -0.97 & -0.04 & -2.02 & 0.21 & -2.40 & -1.74 \\
\hline Gre & 3.61 & 1.22 & 1.71 & 5.71 & 1.55 & 0.31 & 1.05 & 2.00 & -1.41 & 0.23 & -1.76 & -0.97 \\
\hline Ire & 4.99 & 1.29 & 2.78 & 6.72 & 1.70 & 0.28 & 1.32 & 2.17 & -0.48 & 0.03 & -0.53 & -0.42 \\
\hline Ita & 2.82 & 1.19 & 1.45 & 4.83 & 1.47 & 0.31 & 1.05 & 2.00 & 0.43 & 0.17 & 0.18 & 0.71 \\
\hline Net & 1.64 & 0.36 & 0.73 & 2.35 & 2.90 & 0.50 & 2.04 & 3.68 & 0.57 & 0.12 & 0.43 & 0.77 \\
\hline Por & 10.80 & 3.06 & 5.70 & 16.10 & 4.36 & 0.53 & 3.51 & 5.12 & 0.07 & 0.07 & -0.05 & 0.18 \\
\hline Spa & 8.81 & 1.71 & 6.46 & 12.69 & 3.72 & 0.68 & 2.68 & 4.86 & 1.84 & 0.37 & 1.36 & 2.45 \\
\hline \multicolumn{13}{|c|}{ Post-crisis Period } \\
\hline & \multicolumn{4}{|c|}{ CoRisk $_{\text {sov }}(\%)$} & \multicolumn{4}{|c|}{$\operatorname{CoRisk}_{\text {corp }}(\%)$} & & oRist & $a n k(\%$ & \\
\hline Country & Mean & $\mathrm{SD}$ & Min & $\operatorname{Max}$ & Mean & SD & Min & $\operatorname{Max}$ & Mean & SD & Min & $\operatorname{Max}$ \\
\hline Aus & -4.60 & 0.82 & -5.88 & -3.18 & 2.78 & 0.11 & 2.58 & 2.99 & 0.64 & 0.06 & 0.52 & 0.74 \\
\hline Bel & 6.78 & 1.08 & 4.87 & 8.42 & 0.31 & 0.02 & 0.26 & 0.34 & 2.60 & 0.21 & 2.21 & 2.90 \\
\hline Fin & -3.75 & 1.31 & -6.79 & -1.81 & 6.14 & 0.39 & 5.40 & 6.52 & 0.65 & 0.19 & 0.42 & 1.04 \\
\hline Fra & 0.43 & 0.20 & 0.05 & 0.76 & 0.51 & 0.06 & 0.41 & 0.59 & 0.07 & 0.00 & 0.07 & 0.08 \\
\hline Ger & 5.23 & 0.95 & 3.64 & 6.60 & 7.20 & 0.40 & 6.52 & 7.76 & 5.62 & 0.78 & 4.29 & 6.80 \\
\hline Gre & -0.94 & 0.21 & -1.21 & -0.53 & -0.72 & 0.07 & -0.81 & -0.59 & 0.89 & 0.16 & 0.55 & 1.12 \\
\hline Ire & 1.64 & 0.67 & 0.68 & 2.81 & -1.26 & 0.05 & -1.37 & -1.20 & 0.93 & 0.19 & 0.69 & 1.28 \\
\hline Ita & 1.80 & 0.64 & 0.85 & 2.87 & -1.57 & 0.07 & -1.72 & -1.47 & 0.52 & 0.13 & 0.35 & 0.78 \\
\hline Net & 0.82 & 0.24 & 0.46 & 1.19 & 0.62 & 0.11 & 0.45 & 0.79 & 0.18 & 0.24 & -0.11 & 0.62 \\
\hline Por & -4.01 & 0.98 & -5.70 & -2.44 & 1.61 & 0.08 & 1.44 & 1.72 & 1.42 & 0.61 & 0.25 & 2.10 \\
\hline Spa & 2.63 & 1.15 & 0.91 & 4.24 & 1.78 & 0.07 & 1.65 & 1.85 & 4.15 & 0.46 & 3.43 & 4.90 \\
\hline
\end{tabular}

Table 2: Summary statistics of CoRisk $k_{i n}$ measures, for the sovereign, corporate and bank sectors, in the four timewindows

increase in its default probability because of its specific sovereign crisis in 2011, but in the following years it starts performing quite well until reaching very low $P D$ values in 2015 . Italy and Spain show similar values, while core countries behave quite similarly to each other, with the lowest $P D s$ across time.

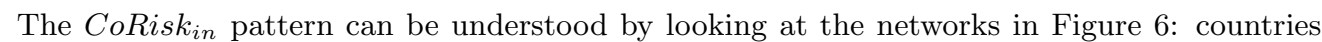
with high positive correlations with peripheral economies, characterized by high $P D s$, have a high CoRisk $_{i n}$ : this is the case, for example, of France and Belgium in the second period, strongly connected, respectively, with Italy and Portugal, and with Italy and Spain. Similarly, Spain

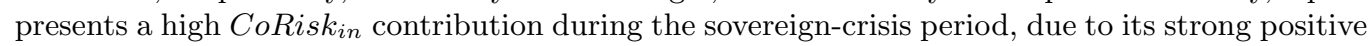
link with Ireland, a particularly troubled country in such years. On the other hand, countries which are negatively or not connected with peripheral ones (such as, for instance, Germany in the second period and Finland and Austria in the last years) have close to zero or negative CoRisk 

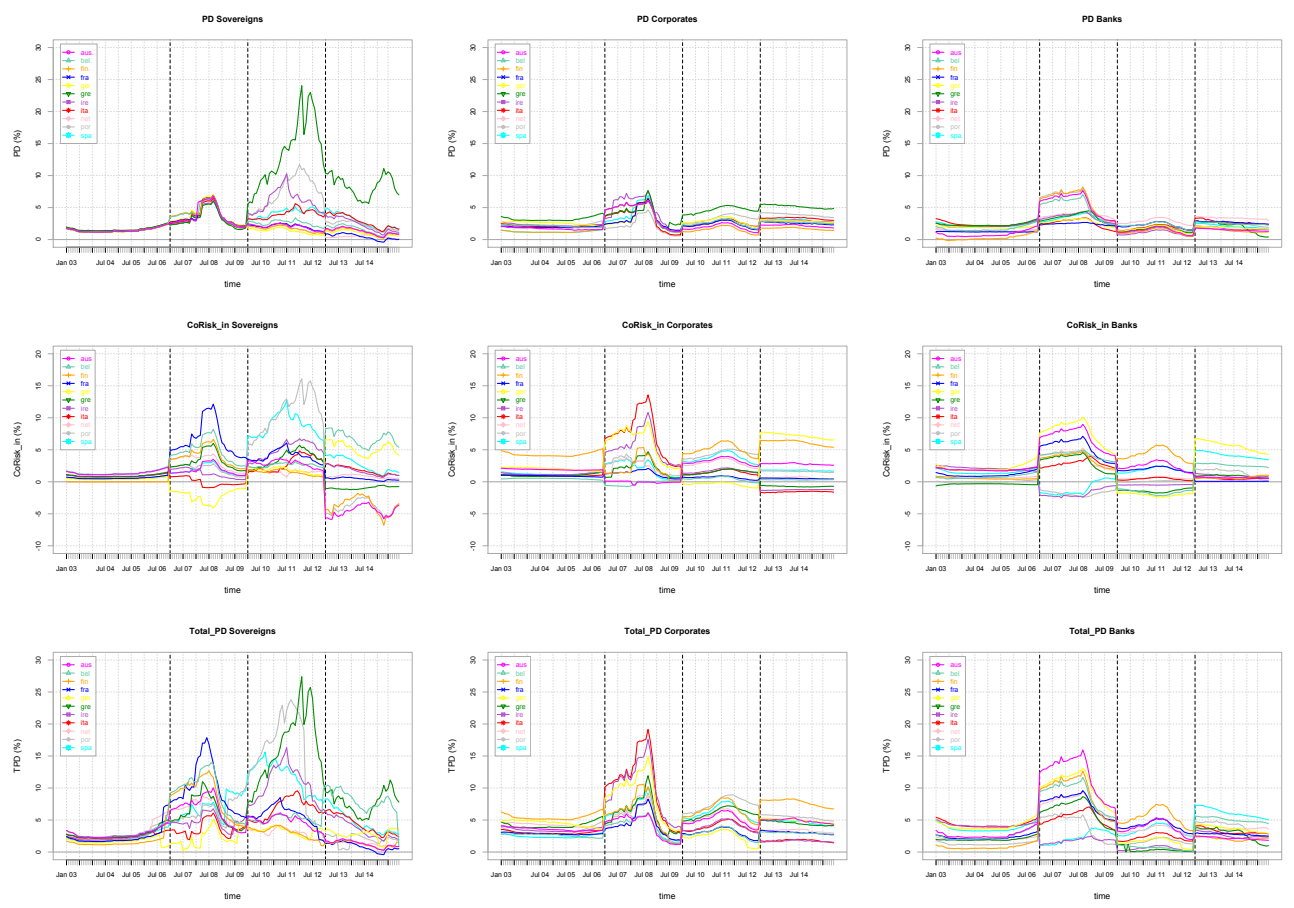

Figure 7: Institution-specific default probabilities $P D_{t,\{1,2,3\}}^{i}$ (top), CoRisk $k_{i n}$ measures (middle) and total default probabilities $T P D_{t,\{1,2,3\}}^{i}$ (bottom) from 2003 until 2015, for the sovereign (left), corporate (middle) and bank (right) sectors

measures.

The final TPD time-evolution is obviously a mix between the institution-specific $P D$ and

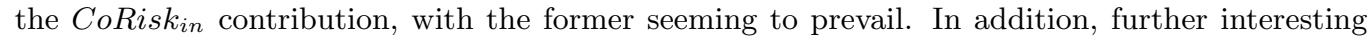
conclusions emerge. In peripheral economies, characterized by high institution-specific $P D s$, the CoRisk $_{i n}$ contribution should be very low; the creation of two distinct clusters, however, creates a sort of "loop", because peripheral economies start being positively connected only between each other, and negatively connected with core ones. For this reason their total default probability $T P D$ is strongly influenced not only by its corresponding institution-specific $P D$, but also by high CoRisk $_{i n}$ values. For the same reason, core economies preserve low total $P D$, even after the inclusion of contagion effects: the only one exception is France, which presents an extremely

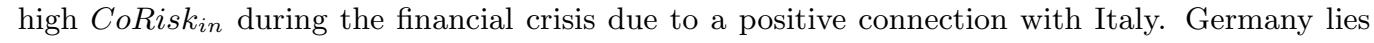
in an intermediate situation, with its CoRisk $k_{i n}$ growing in the recent years along with positive connections with the periphery, in the light of its increasing leading role in the Euro area.

The corporate graphs in Figure 7 show institution-specific PDs less volatile than sovereign ones, across both countries and time. They all peak during the financial crisis and decrease afterwards, remaining almost constant during the following years. In recent times, the ranking of countries reflects the $P D$ situation observed for sovereign risk, with Greece presenting much higher values than all the other countries, and core economies having the lowest ones. This means that, in Europe, sovereign risk has become the main risk driver behind portfolio allocation.

The CoRisk $k_{i n}$ pattern shows that almost all countries suffered contagion effects during the financial crisis and, to a lesser extent, during the sovereign crisis. More precisely, Italy presents the highest CoRisk in values because of its strong positive relationships with Portugal and Spain (see Figure 6).

Differently from what has been observed in the sovereign case, CoRisk $k_{i n}$ is the prevailing effect in the calculation of the total default probability of the corporate sector (with the exception of Germany for the last two periods, because of its very low institution-specific $P D$ values): such a conclusion is supported by Figure 6, which shows that partial correlations are much higher in number and in value, and that a clustering effect is not present.

The bank graphs in Figure 7 reveal that, differently from the sovereign and corporate sectors, the institution-specific PDs of all countries have been influenced only by the financial crisis. Consistently with Figure 5, Belgium, Finland, Portugal and Spain present the highest peaks 
during 2008, because of their high average values of interest rates on deposits.

The CoRisk $k_{i n}$ pattern shows both positive and negative contagion effects during the second time-period, with the former regarding core countries and the latter regarding peripheral countries. More precisely, Germany has a positive contagion effect because of its positive relations with Portugal and Spain, Austria and France because of their positive links to both peripheral and core countries; on the other hand, Ireland, Portugal and Spain are characterized by negative correlations with each other and with the remaining peripheral economies, and are thus characterized by negative CoRisk $k_{i n}$ values. In the post-crisis period, when two distinct clusters start emerging as for the sovereign case, CoRisk $k_{i n}$ increases again both in core and peripheral economies, because of highly positive partial correlations within each cluster.

Similarly to the corporate sector, CoRisk $k_{i n}$ is the prevailing effect in the composition of the total default probability in all time-periods and in almost each country.

In order to understand to what extent a country as a whole is influenced by its neighbours, the aggregate total default probability has been proposed in (2.22): this measure enables us to synthetize contagion effects deriving from different economic sectors into a unique default probability at the country level. The aggregation takes into account intra country contagion effects, that are sterilized. Such results are shown in Figure 8.

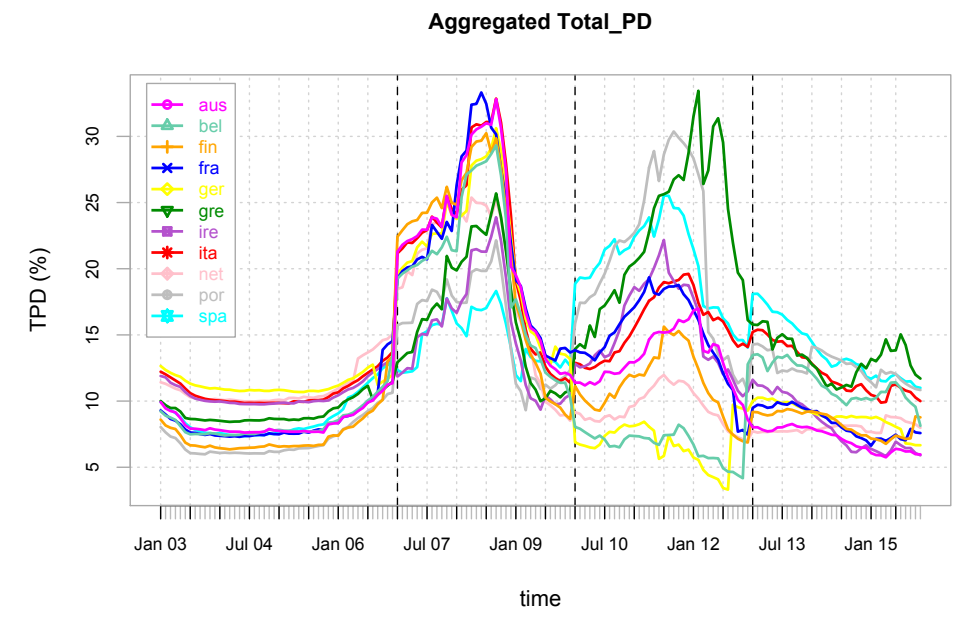

Figure 8: Aggregated total default probabilities TPD $D_{\text {country }}^{i}$ from 2003 until 2015

The analysis of Figure 8 shows how the aggregated total default probability of each country has been influenced by the financial and the sovereign crisis. Two main considerations emerge. First, the financial crisis had a more homogenous impact across countries than the sovereign one: all the aggregated TPD strongly increased during 2008, while in the following time-window a clear distinction between peripheral and core countries appears, with the former characterized by higher values and the latter by lower ones (even decreasing for Germany and Belgium). Two particular countries need a deeper understanding: France, which presents high values mainly because of its positive correlations with peripheral countries, during both the financial and the sovereign crisis; Ireland, characterized by a deep sovereign crisis in 2011, worsen by positive links with peripheral countries (Spain) until 2012, but now performing well, with very low TPD values and positive relations with core economies. Second, the pre- and post- crisis periods appear to be substantially different: during the pre-crisis years, in fact, default probabilities were almost constant and stable across time, and very homogenous across countries; but after the sovereign crisis the situation has become more heterogenous both from a dynamic and a cross-sectional perspective, with high volatilities in all countries and a clear distinction between peripheral (Greece, Spain, Portugal, Italy) and core (Belgium, Finland, the Netherlands, France, Germany, Austria, Ireland) economies. This effect, consistently with Figure 7, means that the sovereign crisis has had a stronger and more persistent impact, that has made sovereign risk the main risk driver. A possible explanation of this effect lies in the different ways peripheral and core economies reacted to the financial crisis, depending on their "sovereign space": peripheral countries were not in "good health" even before the crisis, and even if interest rates on government bonds did not reflect it, the financial crisis triggered problems to emerge. 
Having derived the aggregated default probability at the country level, it is important to understand the evolution of its composition over time. The total $P D$ of a country, in fact, has been calculated as a function of the total default probabilities of its three economic sectors; furthermore, the TPD of each economic sector has been obtained as a function of two contributions:

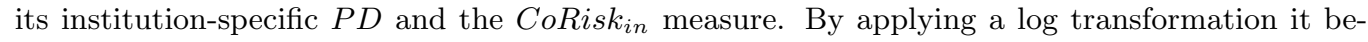
comes possible to disentangle the final default probability of a country into six components: three deriving from the economic sectors, and two deriving from the distinction between institutionspecific $P D$ and CoRisk $_{i n}$ contribution. Since we are interested in analyzing these results for macro-prudential policy purposes, in this context negative CoRisk $k_{i n}$ contributions have been set up to zero, and mean normalized values in the four time-windows have been derived in order to compare histograms rather than continuos time series. The results are shown in Figure 9.
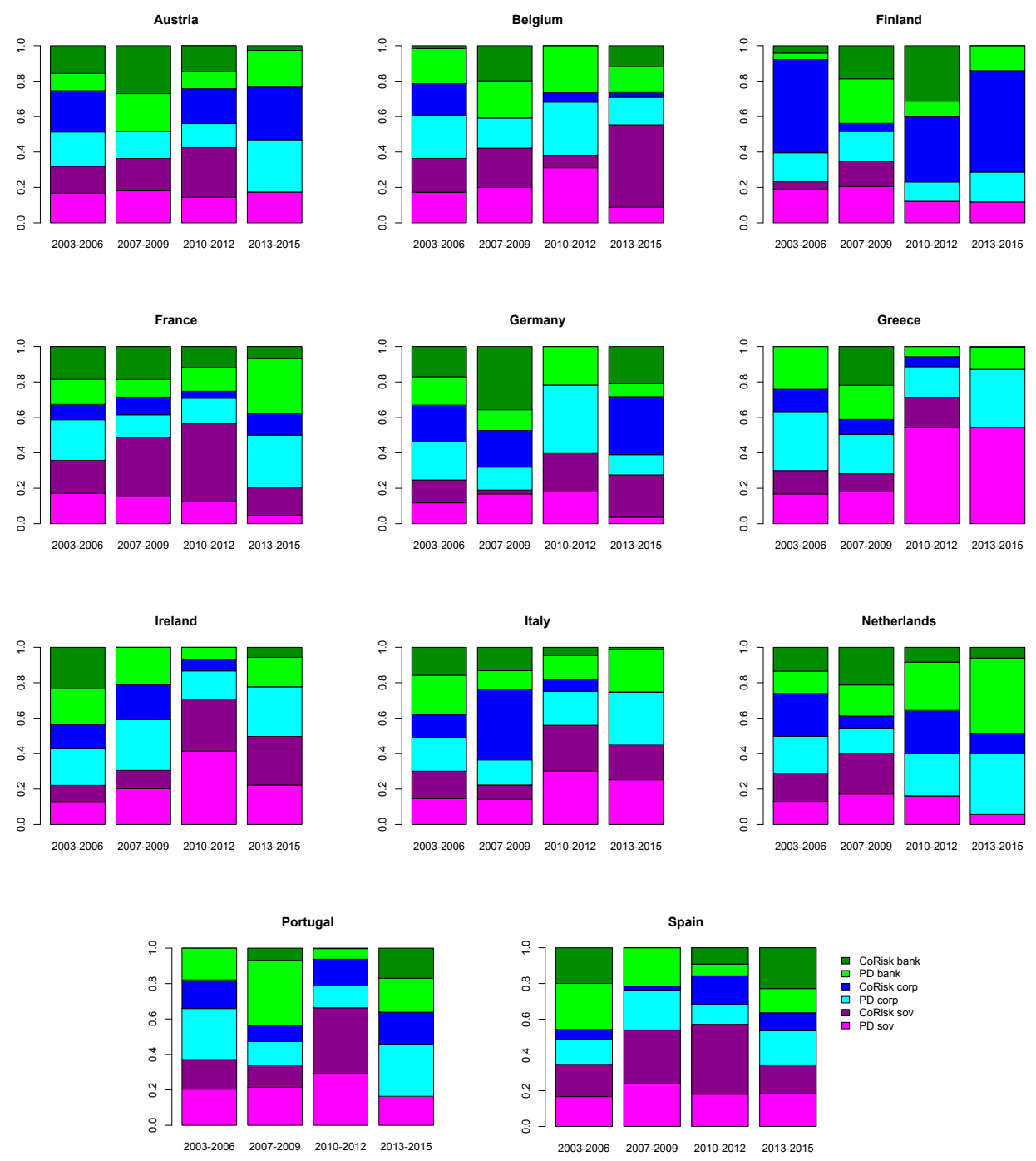

Figure 9: Aggregated total default probabilities contributions: CoRisk $k_{i n}$ and $P D$ components for the three economic sectors in the four time-windows

From Figure 9 one can observe that, for all time periods, the sovereign contribution is larger in peripheral countries than in core ones; furthermore, in core economies the main component of sovereign risk is due to contagion effects, while in peripheral countries the institution-specific $P D$ component is much higher. Moreover, peripheral economies show high CoRisk $k_{i n, s o v}$ contributions because of loop effects, which means positive correlations and, thus, contagion effects between each other. In almost all countries the corporate contribution is stronger during "normal" times, such as before the financial crisis and in the last period, depending on institution-specific PD for 
peripheral economies and on contagion effects in core economies (Austria, Finland, Germany, the Netherlands). Finally, core economies suffered a substantial improvement in contagion effects for the bank sector during the sovereign crisis through their exposition to peripheral banks, while peripheral economies witnessed an increase in their institution-specific bank default probabilities.

Overall, the contribution of the bank and the sovereign sectors to systemic risk increased, in all countries, respectively during the financial and the sovereign crisis, with prevailing contagion effects in core economies, and higher institution-specific $P D s$ and contagion effects deriving as a consequence of clustering in peripheral countries. Note also that the distribution of risk in its six components looks quite homogenous before the financial crisis, while after it the situation is not back to normality, because strong contagion risks persist in core economies, while institutionspecific default probabilities are still high and even worsened by clustering effects in peripheral ones.

For comparative purposes, we have also considered the eigenvector centrality (see e.g. Furfine, 2003; Billio et al., 2012) and the weighted degree, calculated as the sum of all the significant partial correlations, and we have compared the results with the CoRisk in $_{\text {measure. The degrees }}$ of connectivity and the eigenvectors are reported in the Appendix, Table 8, while a comparison between the rankings obtained with our methodology $\left(\right.$ CoRisk $\left._{i n}\right)$ and the degree of connectivity and eigenvector centrality is shown in Table 3.

\begin{tabular}{|c|c|c|c|c|c|c|c|c|c|}
\hline & \multicolumn{3}{|c|}{ Sovereign } & \multicolumn{3}{|c|}{ Corporate } & \multicolumn{3}{|c|}{ Bank } \\
\hline Period & CoRisk & $D C$ & Eigen. & CoRisk & $D C$ & Eigen. & CoRisk & $D C$ & Eigen. \\
\hline \multirow{11}{*}{ 2003-2006 } & Bel & Net & Gre & Fin & Fin & Fin & Ger & Aus & Ger \\
\hline & Aus & Gre & Ita & Ger & Net & Por & Ire & Ita & Aus \\
\hline & Gre & Ita & Por & Net & Ger & Spa & Ita & Ger & Gre \\
\hline & Net & Por & Spa & Aus & Aus & Gre & Aus & Bel & Bel \\
\hline & Ita & Bel & Ire & Spa & Ire & Ire & Spa & Fra & Fin \\
\hline & Ire & Fra & Aus & Ire & Por & Ita & Fra & Spa & Ita \\
\hline & Fra & Ger & Ger & Por & Gre & Aus & Bel & Ire & Fra \\
\hline & Por & Ire & Fra & Gre & Spa & Net & Net & Net & Spa \\
\hline & Spa & Spa & Bel & Ita & Ita & Ger & Fin & Por & Ire \\
\hline & Ger & Aus & Net & Fra & Fra & Fra & Por & Fin & Net \\
\hline & Fin & Fin & Fin & Bel & Bel & Bel & Gre & Gre & Por \\
\hline \multirow{11}{*}{ 2007-2009 } & Fra & Fra & Ger & Ita & Ita & Por & Ger & Ger & Spa \\
\hline & Bel & Spa & Fra & Ger & Ire & Ita & Aus & Aus & Net \\
\hline & Fin & Aus & Net & Ire & Ger & Gre & Fra & Fra & Aus \\
\hline & Gre & Gre & Spa & Por & Fin & Ire & Bel & Net & Bel \\
\hline & Net & Fin & Fin & Spa & Gre & Ger & Net & Gre & Fra \\
\hline & Por & Net & Por & Gre & Por & Fin & Fin & Fin & Ger \\
\hline & Aus & Bel & Aus & Net & Fra & Spa & Gre & Bel & Fin \\
\hline & Spa & Ire & Gre & Fin & Spa & Fra & Ita & Ita & Gre \\
\hline & Ire & Por & Ire & Fra & Net & Net & Spa & Spa & Ita \\
\hline & Ita & Ita & Bel & Aus & Bel & Aus & Ire & Ire & Ire \\
\hline & Ger & Ger & Ita & Bel & Aus & Bel & Por & Por & Por \\
\hline \multirow{11}{*}{ 2010-2012 } & Por & Fra & Fin & Fin & Fin & Por & Fin & Fin & Por \\
\hline & Spa & Spa & Ger & Por & Aus & Ire & Aus & Aus & Spa \\
\hline & Ire & Aus & Net & Spa & Spa & Gre & Fra & Spa & Ita \\
\hline & Fra & Ger & Aus & Aus & Fra & Fin & Spa & Fra & Net \\
\hline & Gre & Net & Bel & Net & Net & Spa & Net & Net & Gre \\
\hline & Aus & Bel & Fra & Ire & Ita & Net & Ita & Ita & Fin \\
\hline & Ita & Por & Spa & Gre & Por & Bel & Por & Por & Aus \\
\hline & Bel & Ita & Por & Ita & Ire & Aus & Ire & Ire & Fra \\
\hline & Ger & Gre & Ita & Fra & Gre & Fra & Gre & Gre & Ire \\
\hline & Net & Fin & Gre & Bel & Ger & Ita & Bel & Ger & Ger \\
\hline & Fin & Ire & Ire & Ger & Bel & Ger & Ger & Bel & Bel \\
\hline \multirow{11}{*}{ 2013-2015 } & Bel & Bel & Por & Ger & Fin & Fin & Ger & Ger & Ger \\
\hline & Ger & Ger & Net & Fin & Ger & Aus & Spa & Spa & Aus \\
\hline & Spa & Ita & Fin & Aus & Aus & Net & Bel & Bel & Spa \\
\hline & Ita & Fra & Bel & Spa & Spa & Spa & Por & Por & Gre \\
\hline & Ire & Spa & Ita & Por & Por & Ita & Ire & Ire & Por \\
\hline & Net & Ire & Ire & Net & Net & Bel & Gre & Gre & Ita \\
\hline & Fra & Por & Ger & Fra & Fra & Ire & Fin & Fin & Fin \\
\hline & Gre & Aus & Fra & Bel & Ita & Gre & Aus & Ita & Bel \\
\hline & Fin & Fin & Spa & Gre & Bel & Ger & Ita & Aus & Ire \\
\hline & Por & Net & Aus & Ire & Ire & Por & Net & Fra & Fra \\
\hline & Aus & Gre & Gre & Ita & Gre & Fra & Fra & Net & Net \\
\hline
\end{tabular}

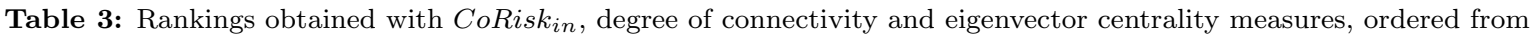
the highest to the lowest

Table 3 shows three kinds of ranking, one for each measure of connectivity, for the three economic sectors and the four time periods: in each list, countries are listed in descendent order. In order to compare the rankings obtained with the CoRisk $k_{i n}$ measure to the other two, a Spearman 
non-parametric correlation test has been applied: the results are shown in Table 4.

\begin{tabular}{lll|ll|ll} 
& \multicolumn{2}{c|}{ Sovereign } & \multicolumn{2}{c|}{ Corporate } & \multicolumn{2}{c}{ Bank } \\
\hline Period & $D C$ & Eigen. & $D C$ & Eigen. & $D C$ & Eigen. \\
\hline \hline $2003-2006$ & 0.436 & 0.136 & 0.936 & 0.373 & 0.764 & 0.245 \\
$2007-2009$ & 0.582 & 0.064 & 0.809 & 0.811 & 0.936 & 0.518 \\
$2010-2012$ & 0.136 & -0.736 & 0.691 & 0.655 & 0.982 & 0.345 \\
$2013-2015$ & 0.736 & 0.018 & 0.927 & 0.245 & 0.982 & 0.573 \\
\hline \hline
\end{tabular}

Table 4: Correlation coefficients between CoRisk $k_{i n}$ rankings and rankings based on, respectively, degree centrality $(D C)$ and eigenvector centrality (Eigen.), for the three economic sectors and the four time-windows

Table 4, which shows correlation coefficients between the rankings obtained with the CoRisk $k_{i n}$ measure and those obtained with the degree of centrality and the eigenvector centrality, reveals

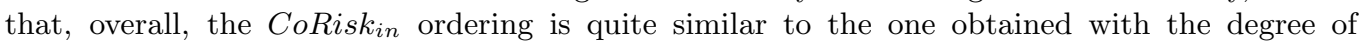
centrality: the difference between the two lies in the fact that the former weights each link in the graph considering not only partial correlations, but also the default probability of neighbours. On the other hand, eigenvector centrality does not take into account weights deriving from the default probability of neighbours and, in addition, it considers the importance of each node in the graph by looking at its relations with other central nodes, so that a node becomes much more important if it is connected to important ones. This mechanism, performed without considering the impact of each node on the basis of its default probability, amplifies the "error", or the distance between CoRisk $_{i n}$ and the eigenvector centrality measure. This effect is particularly evident during the sovereign-crisis period in the sovereign sector.

As we remarked in the methodological section, CoRisk $k_{\text {out }}$ measures how each node in the graph affects its neighbours and, thus, provides an estimation of the systemically importance of each economic sector in each country. The obtained results, compared with CoRisk in ones, are shown in Figure (10).
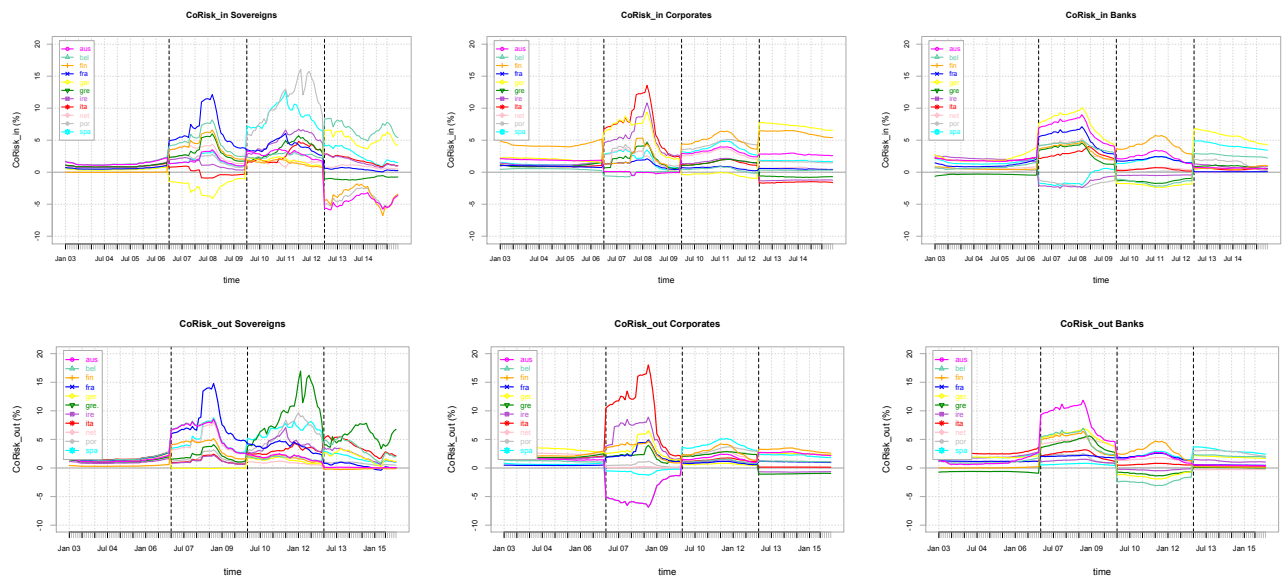

Figure 10: Comparison between CoRisk in $_{\text {(top) and CoRisk }}$ (bottom), from 2003 until 2015 and for the sovereign (left), corporate (middle) and bank (right) sectors

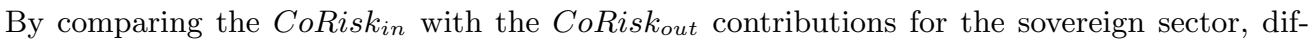
ferent conclusions can be deduced across countries and time. First, during the pre-crisis and the financial crisis periods, the two measures look very similar, while important differences start emerging during the sovereign crisis period, in which it appears clear that Greece is more an exporter rather than an importer of risk, while the situation is reversed for Portugal and Spain. In most recent years, all peripheral countries have the highest, even if decreasing, CoRisk out $_{\text {contri- }}$ butions, since their institution-specific $P D$ is significantly higher than that of core economies. It is interesting to observe that there are not negative CoRisk $k_{\text {out }}$ measures for the sovereign sector, meaning that all european countries overall contribute to increase the default probability of their neighbours.

The incoming and outgoing contributions for the corporate sectors emphasize, once again, the difference between core and peripheral countries, with the latter characterized by higher CoRisk $k_{\text {out }}$ and the former by higher CoRisk $k_{i n}$. Moreover, as in the previous case, one can notice that the two 
CoRisk contributions are very similar during the first two time-periods, while they start diverging afterwards. Same results can be observed for the bank sector. Overall, peripheral (core) countries are more exporter (importer) rather than importer (exporter) of systemic risk; moreover, during the first two periods CoRiskin and CoRisk out are very similar for almost the entire sample, meaning that in those years default probabilities were much more homogenous across european countries than afterwards. This result can be once more explained by the emerging of clustering effects starting from the third period.

\section{Conclusions}

In this work we have proposed a new systemic risk measurement model, based on multivariate stochastic processes, correlation networks and default probabilities. The model has been applied to the economies of the European monetary union. For each country we have considered three spread measures (sovereign spread, corporate spread, bank spread), and we have modelled each of them as a linear combination of two stochastic processes: a country-specific idiosyncratic component and a common systematic factor. We have introduced a correlation network model between all countries, within each sector and across them, thus deriving a statistical representation of the transmission mechanism of systemic risk that correctly takes into account interdependence effects. We have then derived the probability of default for each country and sector, both unconditionally and conditionally on the network structure: the comparison between them allows the definition of a novel risk indicator, the CoRisk, that explicitly measures the contagion effect on the probability of default, including both systematic and systemic components.

From an applied viewpoint, our proposed methodology seems quite effective and efficient, particularly when compared to alternative network based measures, such as the weighted degree and the eigenvector centrality. The main findings deriving from the application of our methodology to the Euro area can be summarized as follows.

Overall, the contribution of the bank and sovereign sectors to systemic risk increased in all countries, respectively during the financial and the sovereign crisis. Sovereign risk is larger in peripheral countries than in core ones: while the main component of sovereign risk is due to contagion effects (CoRisk) in core economies, the institution-specific $P D$ component is much higher in peripheral countries. In addition, peripheral economies show high sovereign risk, because of loop effects with each other deriving from clustering.

Corporate risk appears to be the most important source of risk in "normal" times: before the financial crisis and in the last, post-crisis period. It is mostly determined by contagion effects in core economies and institution-specific $P D$ components in peripheral countries.

Bank risk for core economies suffered a substantial improvement of contagion effects during the sovereign crisis, through their exposition to peripheral banks. On the other hand, peripheral economies witnessed an increase in their institution-specific bank default probabilities and the creation of some loop effects.

The distribution of risk in its components looks quite homogenous before the financial crisis, while after the crisis the situation has not come back to normality, because of persisting contagion effects in core economies, and high institution-specific default probabilities, worsened by clustering effects, in peripheral ones.

To conclude, within the Euro area the sovereign crisis has had a larger impact on systemic risk with respect to the financial crisis. A possible explanation consists in different ways peripheral and core economies reacted to the financial crisis: peripheral countries, with high public debts, had little fiscal space and, therefore, the financial crisis triggered their imbalances to emerge in the subsequent sovereign crisis.

Finally, by comparing in and out contagion effects, peripheral (core) countries appear to be more exporter (importer) rather than importer (exporter) of systemic risk.

\section{Acknowledgements}

We acknowledge the support of the PRIN MISURA. This work is based on the PhD thesis research of Laura Parisi, under the supervision of Paolo Giudici. 


\section{References}

ACHARYA, V.V. 2009. A theory of systemic risk and design of prudential bank regulation. Journal of Financial Stability, 5(3), 224-255.

Acharya, V.V., Pedersen, L.H., Philippon, T., \& Richardson, M. 2010. Measuring Systemic Risk. Technical Report. New York University.

Acharya, V.V., Engle, R., \& Richardson, M. 2012. Capital Shortfall: A New Approach to Ranking and Regulating Systemic Risks. American Economic Review: Papers and Proceedings, 102(3), 59-64.

Acharya, V.V., Drechsler, I., \& Schnabl, P. 2014. A Pyrrhic Victory? Bank Bailouts and Sovereign Credit Risk. Journal of Finance, 69(6), 2689 - 2739.

Adrian, T., \& Brunnermeier, M.K. 2011. CoVar. NBER Working Paper 17454. National Bureau of Economic Research.

Ahelegbey, D.F., Billio, M., \& Casarin, R. 2015. Bayesian Graphical Models for Structural Vector Autoregressive Processes. Journal of Applied Econometrics.

Allen, F., \& Gale, D. 2000. Financial Contagion. Journal of Political Economy, 108(1), 1-33.

Ang, A., \& Longstaff, F.A. 2012. Systemic sovereign credit risk: lessons from the U.S. and Europe. Technical Report. National Bureau of Economic Research.

Barigozzi, M., \& BrownleEs, C. 2013. Nets: Network Estimation for Time Series. Technical Report.

Bartram, S.M., Brown, G.W., \& Hund, J.E. 2007. Estimating systemic risk in the international financial system. Journal of Financial Economics, 86(3), 835-869.

Battiston, S., Delli Gatti, D., Gallegati, M., Greenwald, B., \& Stiglitz, J.E. 2012. Liasons dangereuses: Increasing connectivity risk sharing, and systemic risk. Journal of Economic Dynamics and Control, 36(8), 1121-1141.

Betz, F., Oprica, S., Peltonen, T.A., \& Sarlin, P. 2014. Predicting Distress in European Banks. Journal of Banking and Finance, 45(C), 225-241.

Billio, M., Getmansky, M., Lo, A.W., \& Pelizzon, L. 2012. Econometric measures of connectedness and systemic risk in the finance and insurance sectors. Journal of Financial Economics, 104, 535-559.

Brownlees, C., \& Engle, R. 2012. Volatility, Correlation and Tails for Systemic Risk Measurement. Technical Report. New York University.

Brownlees, C., Hans, C., \& Nualart, E. 2014. Bank Credit Risk Networks: Evidence from the Eurozone Crisis. Technical Report. Universitat Pompeu Fabra.

Chan, K.C., Karolyi, G.A., Longstaff, F.A., \& Sanders, A.B. 1992. An Empirical Comparison of Alternative Models of the Short-Term Interest Rate. Journal of Finance, 47(3), $1209-1227$.

Chong, B.S., LiU, M., \& Shrestha, K. 2006. Monetary transmission via the administered interest rates channel. Journal of Banking and Finance, 30(5), 1467-1484.

Cox, J.C., Ingersoll, J.E.JR, \& Ross, S.A. 1985. A Theory of Term Structure of Interest Rates. Econometrica, 53(2), 385-408.

DAs, S.R. 2015. Matrix Metrics: Network-Based Systemic Risk Scoring. Technical Report. Santa Clara University.

Diebold, F.X., \& Yilmaz, K. 2014. On the network topology of variance decompositions: Measuring the connectedness of financial firms. Journal of Econometrics, 182, 119-134.

Duffie, D., Saita, L., \& Wang, K. 2007. Multi-Period Corporate Default Prediction with Stochastic Covariates. Journal of Financial Economics, 88(3), 635-665. 
Dumitrescu, E., \& Banulescu, D.G. 2014. Which are the SIFIs? A Component Expected Shortfall (CES) Approach to Systemic Risk. Journal of Banking and Finance, 50, 575-588.

Giudici, P., \& Spelta, A. 2015. Graphical Network Models for International Financial Flows. Journal of Business and Economic Statistics, to appear.

Gray, D., Gross, M., Paredes, J., \& Sydow, M. 2013. Modeling Banking, Sovereign and Macro Risk in a CCA Global VAR. Technical Report. International Monetary Fund.

Hautsch, N., Schaumburg, J., \& Schienle, M. 2015. Financial Network Systemic Risk Contributions. Review of Finance, 19(2), 685-738.

IACus, S.M. 2008. Simulation and Inference for Stochastic Differential Equations. Springer.

Kalogeropoulos, K., Dellaportas, P., \& Roberts, G.O. 2011. Likelihood-based inference for correlated diffusions. The Canadian Journal of Statistics, 39(1), 52-72.

Koopman, S.J., Lucas, A., \& SchwaAB, B. 2012. Dynamic factor models with macro, frailty, and industry effects for U.S. default counts: the credit crisis of 2008. Journal of Business and Economic Statistics, 30(4), 521-532.

LAndo, D., \& Nielsen, M.S. 2010. Correlation in corporate defaults: contagion or conditional independence. Journal of Financial Intermediation, 19(3), 355-372.

LongstafF, F.A. 2010. The subprime credit crisis and contagion in financial markets. Journal of Financial Economics, 97(3), 436-450.

Lorenz, J., Battiston, S., \& Schweitzer, F. 2009. Systemic risk in a unifying framework for cascading processes on networks. The European Physical Journal B - Condensed Matter and Complex Systems, 71(4), 441-460.

Mezei, J., \& SARlin, P. 2015. RiskRank: Measuring interconnected risk. Technical Report. RiskLab Finland.

Popescu, A., \& Turcu, C. 2014. Systemic Sovereign Risk in Europe: an MES and CES Approach. Revue d'économie politique, 124(6), 899-925.

RAmsay, B.A., \& SARlin, P. 2015. Ending over-lending: assessing systemic risk with debt to cash flow. International Journal of Finance and Economics, to appear.

SchwaAb, B., Koopman, S.J., \& Lucas, A. 2015. Global Credit Risk: World, Country and Industry Factors. Technical Report. Duisenberg School of Finance - Tinbergen Institute.

Shleifer, A., \& Vishny, R.W. 2010. Unstable banking. Journal of Financial Economics, 97(3), $306-318$.

VASICEK, O. 1977. An equilibrium characterization of the term structure. Journal of Financial Economics, 5, 177-188. 


\section{Appendix}

\begin{tabular}{llll} 
& $a$ & $v$ & $b$ \\
\hline \hline $2003-2006$ & 0.014 & 0.001 & 0.056 \\
$2007-2009$ & 0.899 & 0.355 & 0.569 \\
$2010-2012$ & 0.405 & 0.262 & 0.149 \\
$2013-2015$ & 0.008 & 0.002 & 0.090 \\
\hline \hline
\end{tabular}

Table 5: Estimated parameters of the systematic process $S_{t}$ (3-months Euribor), for the pre-crisis, financial-crisis, sovereign-crisis and post-crisis periods

\begin{tabular}{|c|c|c|c|c|c|c|c|c|c|c|}
\hline \multirow[b]{2}{*}{ Period } & \multirow[b]{2}{*}{ Country } & \multicolumn{3}{|c|}{$y_{t, 1}$ (Sov) } & \multicolumn{3}{|c|}{$y_{t, 2}$ (Corp) } & \multicolumn{3}{|c|}{$y_{t, 3}$ (Bank) } \\
\hline & & $\left(\theta_{1}\right)_{1}$ & $\left(\theta_{2}\right)_{1}$ & $\left(\theta_{3}\right)_{1}$ & $\left(\theta_{1}\right)_{2}$ & $\left(\theta_{2}\right)_{2}$ & $\left(\theta_{3}\right)_{2}$ & $\left(\theta_{1}\right)_{3}$ & $\left(\theta_{2}\right)_{3}$ & $\left(\theta_{3}\right)_{3}$ \\
\hline \multirow{11}{*}{ 2003-2006 } & Aus & 0.319 & 0.085 & 0.073 & 0.365 & 0.092 & 0.029 & 0.101 & 0.035 & 0.009 \\
\hline & Bel & 0.351 & 0.093 & 0.075 & 0.481 & 0.108 & 0.034 & 0.143 & 0.039 & 0.015 \\
\hline & Fin & 0.348 & 0.093 & 0.079 & 0.053 & 0.014 & 0.032 & 0.237 & 0.093 & 0.018 \\
\hline & Fra & 0.388 & 0.103 & 0.077 & 0.828 & 0.191 & 0.041 & 0.998 & 0.285 & 0.033 \\
\hline & Ger & 0.390 & 0.105 & 0.079 & 0.305 & 0.063 & 0.012 & 0.173 & 0.065 & 0.021 \\
\hline & Gre & 0.433 & 0.109 & 0.076 & 0.006 & 0.001 & 0.028 & 0.012 & 0.001 & 0.035 \\
\hline & Ire & 0.333 & 0.090 & 0.077 & 0.190 & 0.041 & 0.036 & 0.011 & 0.001 & 0.042 \\
\hline & Ita & 0.392 & 0.099 & 0.074 & 0.252 & 0.057 & 0.030 & 0.075 & 0.041 & 0.039 \\
\hline & Net & 0.379 & 0.101 & 0.080 & 0.366 & 0.079 & 0.018 & 0.500 & 0.075 & 0.032 \\
\hline & Por & 0.374 & 0.097 & 0.076 & 0.004 & 0.001 & 0.035 & 0.728 & 0.248 & 0.034 \\
\hline & Spa & 0.361 & 0.096 & 0.076 & 0.056 & 0.015 & 0.032 & 0.033 & 0.015 & 0.030 \\
\hline \multirow{11}{*}{ 2007-2009 } & Aus & 0.448 & 0.110 & 0.083 & 1.500 & 0.342 & 0.001 & 0.069 & 0.021 & 0.027 \\
\hline & Bel & 0.333 & 0.082 & 0.080 & 1.497 & 0.324 & 0.001 & 0.070 & 0.019 & 0.025 \\
\hline & Fin & 0.235 & 0.061 & 0.081 & 1.487 & 0.356 & 0.001 & 1.507 & 0.514 & 0.001 \\
\hline & Fra & 0.238 & 0.062 & 0.081 & 1.500 & 0.216 & 0.001 & 0.522 & 0.022 & 0.515 \\
\hline & Ger & 0.145 & 0.045 & 0.093 & 1.243 & 0.319 & 0.001 & 0.401 & 0.012 & 0.523 \\
\hline & Gre & 0.760 & 0.150 & 0.108 & 1.518 & 0.320 & 0.002 & 1.096 & 0.022 & 1.480 \\
\hline & Ire & 0.755 & 0.157 & 0.109 & 1.494 & 0.318 & 0.001 & 0.023 & 0.009 & 0.906 \\
\hline & Ita & 0.635 & 0.143 & 0.074 & 1.507 & 0.347 & 0.001 & 0.001 & 0.011 & 0.568 \\
\hline & Net & 0.231 & 0.061 & 0.080 & 1.483 & 0.351 & 0.001 & 0.001 & 0.006 & 0.620 \\
\hline & Por & 0.796 & 0.183 & 0.091 & 1.507 & 0.288 & 0.001 & 1.497 & 0.099 & 0.001 \\
\hline & Spa & 0.708 & 0.169 & 0.083 & 1.521 & 0.311 & 0.001 & 0.033 & 0.005 & 0.756 \\
\hline \multirow{11}{*}{ 2010-2012 } & Aus & 1.507 & 0.529 & 0.001 & 0.592 & 0.126 & 0.060 & 1.487 & 0.670 & 0.001 \\
\hline & Bel & 1.492 & 0.435 & 0.001 & 0.349 & 0.106 & 0.034 & 0.356 & 0.118 & 0.012 \\
\hline & Fin & 0.030 & 0.032 & 0.112 & 0.232 & 0.106 & 0.047 & 0.099 & 0.047 & 0.025 \\
\hline & Fra & 0.073 & 0.039 & 0.115 & 0.691 & 0.073 & 0.345 & 1.271 & 0.406 & 0.037 \\
\hline & Ger & 0.040 & 0.042 & 0.121 & 0.150 & 0.045 & 0.023 & 0.001 & 0.003 & 0.021 \\
\hline & Gre & 1.835 & 0.102 & 0.593 & 0.362 & 0.058 & 0.046 & 0.407 & 0.148 & 0.094 \\
\hline & Ire & 0.407 & 0.057 & 0.262 & 0.067 & 0.021 & 0.037 & 0.157 & 0.069 & 0.108 \\
\hline & Ita & 0.489 & 0.095 & 0.158 & 0.093 & 0.023 & 0.030 & 0.035 & 0.001 & 0.043 \\
\hline & Net & 1.477 & 0.597 & 0.001 & 0.001 & 0.035 & 0.027 & 0.212 & 0.054 & 0.021 \\
\hline & Por & 0.624 & 0.061 & 0.234 & 0.156 & 0.029 & 0.037 & 0.027 & 0.001 & 0.027 \\
\hline & Spa & 0.710 & 0.129 & 0.162 & 0.115 & 0.031 & 0.028 & 0.038 & 0.008 & 0.019 \\
\hline \multirow{11}{*}{ 2013-2015 } & Aus & 0.050 & 0.057 & 0.168 & 0.001 & 0.034 & 0.015 & 0.001 & 0.116 & 0.007 \\
\hline & Bel & 0.038 & 0.047 & 0.157 & 0.001 & 0.058 & 0.021 & 0.001 & 0.078 & 0.014 \\
\hline & Fin & 0.057 & 0.061 & 0.170 & 0.001 & 0.040 & 0.012 & 0.019 & 0.029 & 0.021 \\
\hline & Fra & 0.047 & 0.053 & 0.154 & 0.057 & 0.028 & 0.036 & 0.250 & 0.091 & 0.035 \\
\hline & Ger & 0.047 & 0.069 & 0.191 & 1.483 & 0.497 & 0.001 & 0.985 & 0.274 & 0.001 \\
\hline & Gre & 1.023 & 0.124 & 0.286 & 0.020 & 0.009 & 0.024 & 1.493 & 0.653 & 0.001 \\
\hline & Ire & 0.038 & 0.052 & 0.159 & 0.484 & 0.155 & 0.018 & 0.057 & 0.042 & 0.030 \\
\hline & Ita & 0.014 & 0.030 & 0.134 & 0.001 & 0.002 & 0.022 & 0.104 & 0.048 & 0.034 \\
\hline & Net & 0.039 & 0.049 & 0.165 & 0.001 & 0.046 & 0.029 & 1.486 & 0.430 & 0.001 \\
\hline & Por & 0.104 & 0.051 & 0.188 & 0.001 & 0.070 & 0.015 & 0.001 & 0.107 & 0.026 \\
\hline & Spa & 0.066 & 0.054 & 0.135 & 1.511 & 0.493 & 0.001 & 0.001 & 0.142 & 0.014 \\
\hline
\end{tabular}

Table 6: Estimated parameters of the idiosyncratic processes $y_{t, 1}^{m}$ (interest rates on 10-years maturity government bonds), $y_{t, 2}^{m}$ (interest rates on loans to non-financial corporates) and $y_{t, 3}^{m}$ (interest rates on deposits) for the pre-crisis, financial-crisis, sovereign-crisis and post-crisis periods 


\begin{tabular}{|c|c|c|c|c|c|c|c|}
\hline \multirow{2}{*}{ Period } & \multirow[b]{2}{*}{ Country } & \multicolumn{2}{|c|}{$Z_{t, 1}$ (Sov) } & \multicolumn{2}{|c|}{$Z_{t, 2}$ (Corp) } & \multicolumn{2}{|c|}{$Z_{t, 3}$ (Bank) } \\
\hline & & $\alpha_{1}$ & $\beta_{1}$ & $\alpha_{1}$ & $\beta_{1}$ & $\alpha_{1}$ & $\beta_{1}$ \\
\hline \multirow{11}{*}{ 2003-2006 } & Aus & -0.095 & -0.772 & 0.572 & 0.267 & -0.435 & -0.950 \\
\hline & Bel & -0.089 & -0.775 & 0.629 & 0.298 & -0.113 & -0.916 \\
\hline & Fin & -0.087 & -0.749 & 0.230 & -0.172 & -0.677 & -0.869 \\
\hline & Fra & -0.103 & -0.782 & 0.401 & -0.091 & -0.346 & -0.981 \\
\hline & Ger & -0.115 & -0.775 & 0.720 & 0.415 & -0.712 & -0.939 \\
\hline & Gre & -0.040 & -0.759 & 0.346 & -0.550 & -1.031 & -0.958 \\
\hline & Ire & -0.096 & -0.755 & 0.611 & 0.240 & -0.950 & -0.895 \\
\hline & Ita & -0.043 & -0.758 & 0.486 & 0.025 & -1.318 & -0.812 \\
\hline & Net & -0.102 & -0.772 & 0.577 & 0.170 & -0.451 & -0.888 \\
\hline & Por & -0.070 & -0.754 & 0.201 & -0.520 & -0.442 & -0.830 \\
\hline & Spa & -0.101 & -0.774 & 0.268 & -0.109 & -1.015 & -0.871 \\
\hline \multirow{11}{*}{ 2007-2009 } & Aus & 0.449 & -0.990 & 0.298 & -0.926 & 0.818 & -0.994 \\
\hline & Bel & 0.357 & -0.960 & 0.298 & -0.926 & 0.521 & -0.996 \\
\hline & Fin & 0.481 & -0.991 & 0.318 & -0.889 & 1.046 & -0.988 \\
\hline & Fra & 0.497 & -0.990 & 0.286 & -0.982 & 0.686 & -0.995 \\
\hline & Ger & 0.753 & -0.980 & 0.226 & -0.991 & 0.859 & -0.978 \\
\hline & Gre & 0.253 & -0.980 & 0.050 & -0.968 & 0.470 & -0.889 \\
\hline & Ire & 0.295 & -0.986 & 0.052 & -0.832 & 0.621 & -0.963 \\
\hline & Ita & 0.353 & -0.990 & 0.103 & -0.880 & 1.167 & -0.947 \\
\hline & Net & 0.496 & -0.991 & 0.276 & -0.984 & 0.511 & -0.982 \\
\hline & Por & 0.385 & -0.988 & -0.055 & -0.871 & 0.991 & -0.992 \\
\hline & Spa & 0.443 & -0.992 & 0.207 & -0.926 & 0.646 & -0.936 \\
\hline \multirow{11}{*}{ 2010-2012 } & Aus & 0.637 & -0.167 & 0.373 & -0.929 & 0.207 & -0.969 \\
\hline & Bel & 0.854 & 0.438 & 0.473 & -0.971 & 0.438 & -0.932 \\
\hline & Fin & 0.584 & -0.185 & 0.271 & -0.930 & 0.150 & -0.964 \\
\hline & Fra & 0.593 & -0.318 & 0.452 & -0.966 & 0.418 & -0.983 \\
\hline & Ger & 0.498 & -0.238 & 0.527 & -0.963 & 0.287 & -0.977 \\
\hline & Gre & 0.938 & -0.054 & 0.766 & -0.432 & 0.309 & -0.860 \\
\hline & Ire & 0.968 & 0.753 & 0.501 & -0.793 & 0.149 & -0.785 \\
\hline & Ita & 0.781 & -0.178 & 0.542 & -0.735 & 0.385 & -0.851 \\
\hline & Net & 0.567 & -0.235 & 0.463 & -0.994 & 0.526 & -0.950 \\
\hline & Por & 0.926 & 0.298 & 0.697 & -0.399 & 0.357 & -0.746 \\
\hline & Spa & 0.738 & -0.468 & 0.528 & -0.802 & 0.321 & -0.825 \\
\hline \multirow{11}{*}{ 2013-2015 } & Aus & 0.974 & 0.731 & 0.889 & 0.781 & 0.948 & 0.399 \\
\hline & Bel & 0.982 & 0.788 & 0.984 & 0.694 & 0.972 & 0.478 \\
\hline & Fin & 0.976 & 0.765 & 0.883 & 0.507 & 0.959 & 0.555 \\
\hline & Fra & 0.830 & 0.769 & 0.968 & 0.394 & 0.935 & -0.279 \\
\hline & Ger & 0.969 & 0.754 & 0.981 & 0.597 & 0.952 & 0.325 \\
\hline & Gre & 0.980 & -0.315 & 0.996 & 0.832 & 0.991 & 0.859 \\
\hline & Ire & 0.987 & 0.777 & 0.910 & -0.932 & 0.942 & 0.238 \\
\hline & Ita & 0.989 & 0.761 & 0.992 & 0.798 & 0.964 & 0.285 \\
\hline & Net & 0.011 & 0.464 & 0.981 & 0.624 & 0.966 & 0.163 \\
\hline & Por & 0.830 & 0.769 & 0.993 & 0.815 & 0.995 & 0.909 \\
\hline & Spa & 0.985 & 0.681 & 0.993 & 0.857 & 0.974 & 0.596 \\
\hline
\end{tabular}

Table 7: Weight coefficients of the two components of the general processes $Z_{t, 1}^{m}$ (sovereign spread), $Z_{t, 2}^{m}$ (corporate spread) and $Z_{t, 3}^{m}$ (bank spread), for the pre-crisis, financial-crisis, sovereign-crisis and post-crisis periods 


\begin{tabular}{|c|c|c|c|c|c|c|c|}
\hline \multirow{2}{*}{ Period } & \multirow[b]{2}{*}{ Country } & \multicolumn{2}{|c|}{ Sovereign } & \multicolumn{2}{|c|}{ Corporate } & \multicolumn{2}{|c|}{ Bank } \\
\hline & & $\overline{\mathrm{DC}}$ & Eigen. & $\overline{\mathrm{DC}}$ & Eigen. & $\overline{D C}$ & Eigen. \\
\hline \multirow{11}{*}{ 2003-2006 } & Aus & 0.701 & 0.227 & 0.931 & 0.277 & 21.448 & 0.990 \\
\hline & Bel & 0.971 & 0.158 & 0.161 & 0.000 & 0.995 & 0.356 \\
\hline & Fin & 0.015 & 0.000 & 2.026 & 1.000 & 0.186 & 0.121 \\
\hline & Fra & 0.916 & 0.196 & 0.227 & 0.000 & 0.761 & 0.000 \\
\hline & Ger & 0.915 & 0.211 & 1.100 & 0.000 & 1.236 & 1.000 \\
\hline & Gre & 1.161 & 1.000 & 0.597 & 0.520 & -0.308 & 0.781 \\
\hline & Ire & 0.877 & 0.231 & 0.791 & 0.378 & 0.707 & 0.000 \\
\hline & Ita & 1.061 & 0.954 & 0.516 & 0.325 & 1.324 & 0.000 \\
\hline & Net & 1.219 & 0.125 & 1.149 & 0.226 & 0.273 & 0.000 \\
\hline & Por & 0.979 & 0.578 & 0.717 & 0.710 & 0.240 & 0.000 \\
\hline & Spa & 0.873 & 0.340 & 0.573 & 0.694 & 0.739 & 0.000 \\
\hline \multirow{11}{*}{ 2007-2009 } & Aus & 1.064 & 0.210 & -0.106 & 0.099 & 1.610 & 0.894 \\
\hline & Bel & 0.721 & 0.010 & -0.044 & 0.050 & 0.821 & 0.806 \\
\hline & Fin & 0.916 & 0.307 & 0.712 & 0.298 & 0.962 & 0.244 \\
\hline & Fra & 2.402 & 0.973 & 0.435 & 0.135 & 1.185 & 0.548 \\
\hline & Ger & -0.185 & 1.000 & 1.439 & 0.710 & 1.921 & 0.466 \\
\hline & Gre & 1.019 & 0.189 & 0.691 & 0.794 & 1.038 & 0.000 \\
\hline & Ire & 0.512 & 0.182 & 1.512 & 0.758 & 0.021 & 0.000 \\
\hline & Ita & 0.156 & 0.000 & 2.383 & 0.938 & 0.784 & 0.000 \\
\hline & Net & 0.887 & 0.585 & 0.242 & 0.118 & 1.093 & 0.927 \\
\hline & Por & 0.451 & 0.277 & 0.639 & 1.000 & -0.012 & 0.000 \\
\hline & Spa & 1.309 & 0.423 & 0.276 & 0.210 & 0.154 & 1.000 \\
\hline \multirow{11}{*}{$2010-2012$} & Aus & 1.170 & 0.388 & 1.379 & 0.000 & 1.379 & 0.000 \\
\hline & Bel & 0.872 & 0.220 & -1.070 & 0.174 & -1.070 & 0.000 \\
\hline & Fin & 0.651 & 1.000 & 2.592 & 0.698 & 2.592 & 0.000 \\
\hline & Fra & 1.663 & 0.000 & 0.911 & 0.000 & 0.911 & 0.000 \\
\hline & Ger & 1.009 & 0.862 & -0.794 & 0.000 & -0.794 & 0.000 \\
\hline & Gre & 0.676 & 0.000 & -0.632 & 0.836 & -0.632 & 0.217 \\
\hline & Ire & 0.514 & 0.000 & -0.100 & 0.880 & -0.100 & 0.000 \\
\hline & Ita & 0.765 & 0.000 & 0.174 & 0.000 & 0.174 & 0.356 \\
\hline & Net & 0.940 & 0.612 & 0.357 & 0.301 & 0.357 & 0.332 \\
\hline & Por & 0.813 & 0.000 & 0.047 & 1.000 & 0.047 & 1.000 \\
\hline & Spa & 1.614 & 0.000 & 1.204 & 0.516 & 1.204 & 0.482 \\
\hline \multirow{11}{*}{ 2013-2015 } & Aus & 0.069 & 0.000 & 1.381 & 0.650 & 0.125 & 0.728 \\
\hline & Bel & 2.242 & 0.565 & 0.025 & 0.192 & 1.023 & 0.150 \\
\hline & Fin & -0.147 & 0.619 & 2.011 & 1.000 & 0.316 & 0.268 \\
\hline & Fra & 0.784 & 0.000 & 0.213 & 0.000 & -0.012 & 0.059 \\
\hline & Ger & 1.883 & 0.000 & 1.872 & 0.000 & 2.773 & 1.000 \\
\hline & Gre & -0.705 & 0.000 & -0.192 & 0.019 & 0.391 & 0.676 \\
\hline & Ire & 0.571 & 0.068 & -0.183 & 0.126 & 0.513 & 0.094 \\
\hline & Ita & 1.286 & 0.312 & 0.036 & 0.216 & 0.189 & 0.353 \\
\hline & Net & -0.200 & 0.769 & 0.383 & 0.616 & -0.232 & 0.002 \\
\hline & Por & 0.540 & 1.000 & 0.479 & 0.000 & 0.878 & 0.635 \\
\hline & Spa & 0.584 & 0.000 & 0.707 & 0.348 & 1.805 & 0.719 \\
\hline
\end{tabular}

Table 8: Degree of connectivity (DC) and eigenvector centrality (Eigen.) measures for the three economic sectors and for the pre-crisis, financial-crisis, sovereign-crisis and post-crisis periods 